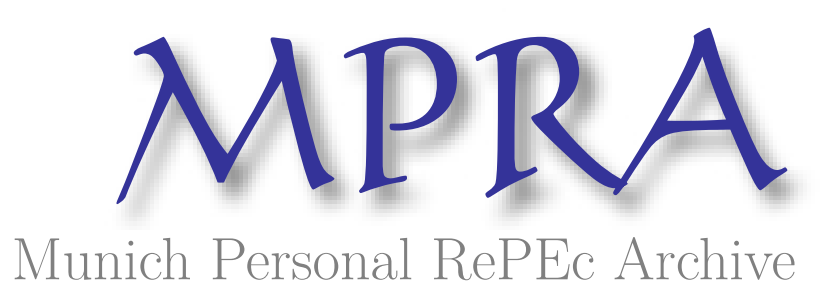

\title{
Denial vs. Punishment: Strategies Shape War, but War Itself Affects Strategies
}

Nakao, Keisuke

16 September 2017

Online at https://mpra.ub.uni-muenchen.de/81418/

MPRA Paper No. 81418, posted 17 Sep 2017 14:10 UTC 


\title{
Denial vs. Punishment: Strategies Shape War, but War Itself Affects Strategies*
}

\author{
Keisuke Nakao ${ }^{\dagger}$
}

September 16, 2017

\begin{abstract}
Formal models of war termination have been developed along two major approaches: in one, war is interpreted as a series of battles, where belligerents exchange denial campaigns; in the other, war is illustrated as a process of bargaining with mutual punishments. In integrating these two approaches, we build a dynamic model of war, where two belligerents choose to attack each other on either force or value in every period. In the early stage of war when military strength is balanced between the belligerents, they both conduct (counterforce) denial campaigns. However, toward the end when one side has depleted its capabilities of fighting, the other side switches to (countervalue) punishment campaigns to coerce the opponent into capitulation. Accordingly, while denials largely determine a war's outcome, punishments can influence its duration. Unlike existing studies, our theory illuminates the two-way causal relationship, where military strategies shape war, while war itself affects the strategies.

JEL classifications: D74; F51.
\end{abstract}

Keywords: aerial bombardment, choice of target, counterforce vs. countervalue, denial vs. punishment, military strategy, reverse causality, use of force.

*Acknowledgment: I thank Sean Zeigler for valuable comments. An earlier version of this paper was presented at the 2017 Annual Meeting of the Midwest Political Science Association. All errors are my own.

${ }^{\dagger}$ College of Business and Economics. University of Hawaii at Hilo. 200 W. Kawili St., Hilo, HI 96720 USA. E-mail: keisuken@hawaii.edu. 
The Fighters are our salvation but the Bombers alone provide the means of victory.

Winston Churchill ${ }^{1}$

\section{Introduction}

Theorists in International Relations have developed formal models of war termination along two major approaches. Models in one approach focus on the political aspect of war, where two belligerents strive to compel each other's surrender by exerting the power to hurt (Schelling 1966). By nature, this approach consorts with bargaining models of war (Fearon 2004, 2007; Filson and Werner 2002, 2004; Leventoğlu and Slantchev 2007; Powell 2004a, 2004b, 2012; Slantchev 2003a; Wagner 2000). In many of these "punishment" models, wartime costs - in addition to the revealed information as to the opponent's resolve and/or strength - constitute the major motivation for belligerents to terminate war, while the relative strength between belligerentsnamely the probability for either belligerent to defeat its opponent-remains fixed (but often uncertain) throughout war.

The other approach puts emphasis on the military aspect of war in that the relative strength can change through fighting, as portrayed in combat models by Lanchester (1916) and his followers (Bellany 1999; Langlois and Langlois 2009, 2012) as well as in random-walk models (Slantchev 2003b; Smith 1998; Smith and Stam 2003, 2004). These models commonly presume war to be a series of battles, where belligerents struggle to overpower each other by wielding the ability to diminish the enemy's military strength, or what might be called the power to weaken. According to these "denial" models, a loss in battle can cause a disadvantageous military imbalance, which in turn generates the incentive to surrender. While the punishment models have been inspired by Clausewitz's (1832: 87) renowned definition of war as "merely the continuation of policy by other means" (Reiter 2003; Wagner 2000), the denial models may better reflect Clausewitz's alternative definition of war as "nothing but a duel in a larger scale" (p. 75$){ }^{2}$

\footnotetext{
${ }^{1}$ This statement is inscribed on the wall of the RAF Bomber Command Memorial in London.

${ }^{2}$ Clausewitz (1832: 90) once stipulated that three broad objectives of military engagement are "the armed forces, the country, and the enemy's will." Following his taxonomy, formal models of war can be categorized into three kinds: war as exchange of attacks on armed forces in the combat models above; on country (or "fort") in the random-walk models; and on will in the bargaining models. Some models can overlap - depicting shifts of military balance while exploring bargaining (Langlois and Langlois 2009, 2012; Slantchev 2003b; Smith and Stam 2004). Among the three objectives,
} 
This dichotomy in models of war may mirror the long-lasting debate over the use and effectiveness of military aviation. ${ }^{3}$ Early proponents of air power, on one side of the debate, were affirmative of air bombings to destroy not only military targets in the battlefront but also civilian targets behind there such as the economic infrastructure, commercial districts, residential areas, and in particular "the will of the people" (Douhet 1921). They maintain that strategic bombings on civilians can pressure the targeted state into capitulation, or concession at least, by raising the societal costs of further prosecuting the war. In addition to prominent advocates including William Mitchell, Alexander de Seversky, and Hugh Trenchard (MacIsaac 1986), ${ }^{4}$ many military strategists and commanders during WWII - including Winston Churchill, Arthur Harris, Franklin Roosevelt, Harry Truman, and Curtis LeMay as they ordered aerial bombings on cities in massive scales - believed in the coercive effects of punishment campaigns (Biddle 1995, 2002). ${ }^{5}$

On the other side of the debate, a majority of contemporary scholars have cast skeptical views toward aerial bombings that aim to inflict suffering on civilians (Carr 2003: 190-191, 248-251; Horowitz and Reiter 2001; Kocher et al. 2011; Lambeth 2000; Pape 1996). ${ }^{6}$ While rejecting punishment campaigns as a means of coercion, they contend that the political objectives of war can be better pursued by denial campaigns - consisting of air support and interdiction (Horowitz and Reiter 2001: 152; Pape 1996: 69-79) — that are projected onto the enemy's military capacity (e.g., fielded forces, ordnance, arsenals, and weapon plants). According to their tenet, the targeted state is forced into capitulation once it depletes its capabilities of fighting.

In sharp contrast to the literature on aerial bombardment, where denial campaigns

Clausewitz (1832: 229) prioritized the armed forces. Liddell-Hart (1967: 352) notably disagreed.

${ }^{3}$ Our wording of "denial" and "punishment" follows the literature on aerial bombardment (Horowitz and Reiter 2001; Pape 1996; Toft and Zhukov 2012). Others studies refer to these terms as "attrition" and "exhaustion," respectively (Echevarria 2017: 30-46).

${ }^{4}$ William Mitchell is the Father of the U.S. Air Force, Hugh Trenchard the Father of the Royal Air Force, Alexander de Seversky the author of the treatise Victory through Air Power filmed by Disney. The earliest proponents of air power in the West-Edgar Gorrell and Lord Tiverton-were also in favor of mass bombing (Williams 1996).

${ }^{5}$ The word "strategy" has at least two meanings - one in the military sense, and the other in the game-theoretic sense. For what follows, we use "campaign" to mean a choice of target in war and "strategy" (without "military" as its adjective) to refer to its game-theoretic sense unless their meanings are obvious.

${ }^{6}$ Some exceptions in (partial) favor of punishment include: Arreguín-Toft (2001); Stam (1996: 137-139); for air power, Mueller (1998: 205); Warden (1997); Watts (1997: 162-163); and for land power, Lyall (2009). 
are regarded as a more effective means of coercion than punishment campaigns (Belkin et al. 2000; Biddle 2002; Pape 1996; for drone strikes, Johnston and Sarbahi 2016), the punishment models have been more prevalent than the denial models in the theoretical literature (Pape 1996: 7-8). The discrepancy between the aerial and theoretical literature has been persistent, possibly because we still lack a proper theoretical instrument with which to address the choice between (counterforce) denial and (countervalue) punishment in war. ${ }^{7}$ This choice problem has little relevance to army or navy but is significant for the use of air force (Freedman 2003: 5) and nuclear weapons (Ball 1983; Long 2008: 23-52). ${ }^{8}$

We thus develop a formal model in a synthetic approach that incorporates both denial and punishment campaigns as alternatives. In other words, our model features a dilemma faced by belligerents in choosing the target of attacks between force ("guns") and value ("butter"). ${ }^{9}$ Major questions are: How does (and should) a belligerent choose the target of attacks between force and value?; How does (and should) the targeted belligerent react against these attacks?; How do their choices influence the outcome and duration of war? To the best of our knowledge, our research is the first theoretical attempt to explicitly study this choice problem in a dynamic context.

Our model is built upon the standard war-of-attrition model (Maynard Smith 1974) but critically differs from it in that: (i) each of two belligerents possesses some military units ("arms") at a war's onset; (ii) they choose one of "denial," "punishment," and "surrender" in every period; (iii) while "denial" can weaken the enemy by destroying his military units, "punishment" hurts him by inflicting costs. ${ }^{10}$ They fight a series of battles, where a loss results in a reduction of one military unit. The war ends when either belligerent exhausts all its military units (all-out war) or when either surrenders (limited war). By seeking the rationale for a belligerent's choice and change of targets during war, we illuminate the two-way causal relationship between military strategies and war-military strategies influence war, and vice versa.

\footnotetext{
${ }^{7}$ While some weapons (e.g., MD system for denial, ICBM for punishment) are target-specific, others (multi-role fighters, cruise missiles) can be used for denial and punishment interchangeably.

${ }^{8}$ An air force can choose the target of attacks more flexibly than an army or navy can. As Stanley Baldwin warned in his famous 1932 speech, unlike ground and naval forces, "the bomber will always get through."

${ }^{9}$ Unlike the literature on arms races which commonly depict the production tradeoff between guns and better, ours is of the tradeoff concerning destruction.

${ }^{10}$ Denial here includes not just denial of punishments (Slantchev 2003a) but also denial of denials (i.e., reduction of an opponent's denial capacity). By coercing the targeted belligerent to surrender, punishment can function to shorten a war.
} 
The rest of the article proceeds as follows. Section 2 reviews the literature on military strategy. Section 3 provides the model of war, which will be solved in Section 4 and extended in Section 5. Section 6 elucidates our theory with the Pacific War as an illustrative case. Section 7 summarizes our theoretical findings and discusses further implications toward empirical studies and international laws. Long proofs are left in Appendix. 


\section{The Literature on Military Strategy}

For the past few decades, empirical studies have discovered the determinants and effects of military strategy. ${ }^{11}$ According to them, a military strategy is determined by a variety of both external and internal factors. The external factors include: relative military capabilities, war duration, and battle deaths, all of which matter for the decision to resort to civilian victimization (Downes 2008: 65); institutionalized alliances, which tend to promote a maneuver strategy (Wallace 2008). The internal factors are: unstable autocracy, which may rely on a high-variance strategy (Goemans 2000); military culture as a major root of submarine attacks against merchant ships, aerial bombing on nonmilitary targets, and use of poison gas (Legro 1995); democracy, advanced industry, and war experience, all of which are influential on a belligerent's choice out of maneuver, attrition, and punishment (Reiter and Meek 1999).

The empirical literature has also investigated the effects of military strategy on war's outbreak, duration, and outcome. To recap their findings on the outbreak, Epstein (1987) demonstrated that the U.S. direct conventional defense could effectively deter the Soviet aggression in the Persian Gulf; Mearsheimer (1983) and Reiter (1999) revealed the fragility of conventional deterrence against a britzkrieg or maneuver strategy. Regarding the duration, as Bennett and Stam (1996), Reiter and Stam (2002) and Stam (1996) claimed, a maneuver strategy can shorten war, while a punishment strategy tends to make it longer. As for the outcome, Arreguin-Toft (2011) maintained that the combination of direct and indirect strategies matters for asymmetric warfare; Biddle (2004) underscored the superiority of the modern system, or a tightly interrelated complex of various techniques at the tactical and operational levels of war; Carverley (2010/11) attributed the U.S. failure against the Vietcong to its capital-intensive strategy; according to Reiter and Stam (1998, 2002) and Stam (1996), maneuver and punishment stand valid against attrition.

While the empirical literature has grown and matured as shown above, the theoretical studies on military strategy have remained sparse. Into bargaining models with incomplete information, some forms of military strategy have been incorporated such as feigning weakness (Slantchev 2010), fait accompli (Lindsey 2015), and indirect strategy (Tarar 2016). In a non-bargaining context, the choice problem as to

\footnotetext{
${ }^{11}$ The literature on military strategy has grown in part to counter the theory of offence-defense balance (cf. Brown et al. 2004). The counterarguments are found in Mearsheimer (1983); Reiter (1999); and Reiter and Meek (1999).
} 
the allocation of military resources has been theorized at the operational level in the sense that the models focus on specific battles or certain theaters rather than on war as a whole (for offensive resources, Borel 1921; Golman and Page 2009; Hart 2008; Roberson 2006; Roberson and Kvasov 2012; for defensive resources, Bier et al. 2007; Powell 2007a, 2007b, 2009; Wang and Bier 2011; Zhuang and Bier 2007, 2011).

With few exceptions (Bennett and Stam 1998; Goemans 2000; Pape 1996: 52), most of the existing empirical and theoretical studies have commonly presumed military strategies to be chosen at war's onset and fixed throughout. Although the presumption of fixed military strategy sounds reasonable for certain (especially land and sea) warfare, where an operation is difficult to modify once invoked, it has limited applicability to a class of other (aerial) warfare, where belligerents flexibly adjust their means and plans to evolving strategic circumstances. For this reason, we develop a dynamic model that allows the choice of targets ("campaign" in our words) to be changed during war. With the setting of flexible military strategy, it is enabled to capture the two-way causal relationship between military strategies and war. 


\section{The Model of War as Exchange of Denials and Punishments}

Our model aims to analyze how belligerents choose and change the targets of their attacks in the midst of war and also how they react when attacked. In the model, two belligerents attack each other's either force or value over time. While an attack on force can reduce the opponent's military capabilities, an attack on value inflicts heavier costs on the opponent.

\subsection{Analogy to Street Fight}

The war that our model represents is analogous to the following scenario on a street fight, which may inspire the reader's imagination. There are two rogues fighting on a street over indivisible booty (say, a sexy girl). Each of them has two "arms" and one "head." In the fight, they hit each other on the "arm" or on the "head." While a hit on the "arm" may break it with a certain probability, a hit on the "head" inflicts more pain for sure. They continue to hit each other repeatedly until the fight ends when either rogue has both his "arms" broken or when either rogue runs away from the scene.

\subsection{Counterforce vs. Countervalue}

The model depicts a war as a series of at most three "battles" fought between two belligerents $(i, j \in\{\alpha, \beta\})$. Each $i$ of them possesses two military units at the war's onset, or $m_{i, 1}=2$, where $m_{i, t} \in\{0,1,2\}$ denotes $i$ 's strength in time period $t .^{12}$ In each period $t=1,2,3, \cdots$, they simultaneously choose one of the three options: to attack the opponent's force ("denial"), to attack its value ("punishment"), or to "surrender" $\left(\sigma_{i} \in\{D, P, S\}\right)$. While a denial campaign weakens the opponent, a punishment campaign hurts him.

If $i$ adopts a denial, he can "win" a battle with a certain probability that depends on $i$ 's relative strength to $j$ 's, or $\frac{\left(m_{i, t}\right)^{L}}{\left(m_{\alpha, t}\right)^{L}+\left(m_{\beta, t}\right)^{L}}$, where $L \geq 0$ is Lanchester's (1916)

\footnotetext{
${ }^{12}$ The setting of $m_{i, 1}=2$ is helpful to simplify the transition dynamics (Figure 1 ) and also to reduce the problem of multiple equilibria. Even without assuming more than two military units, $i$ 's relative (absolute) strength can be controlled by manipulating later-defined $L\left(c_{m_{i, t}}^{P}\right)$, which will be defined later.
} 


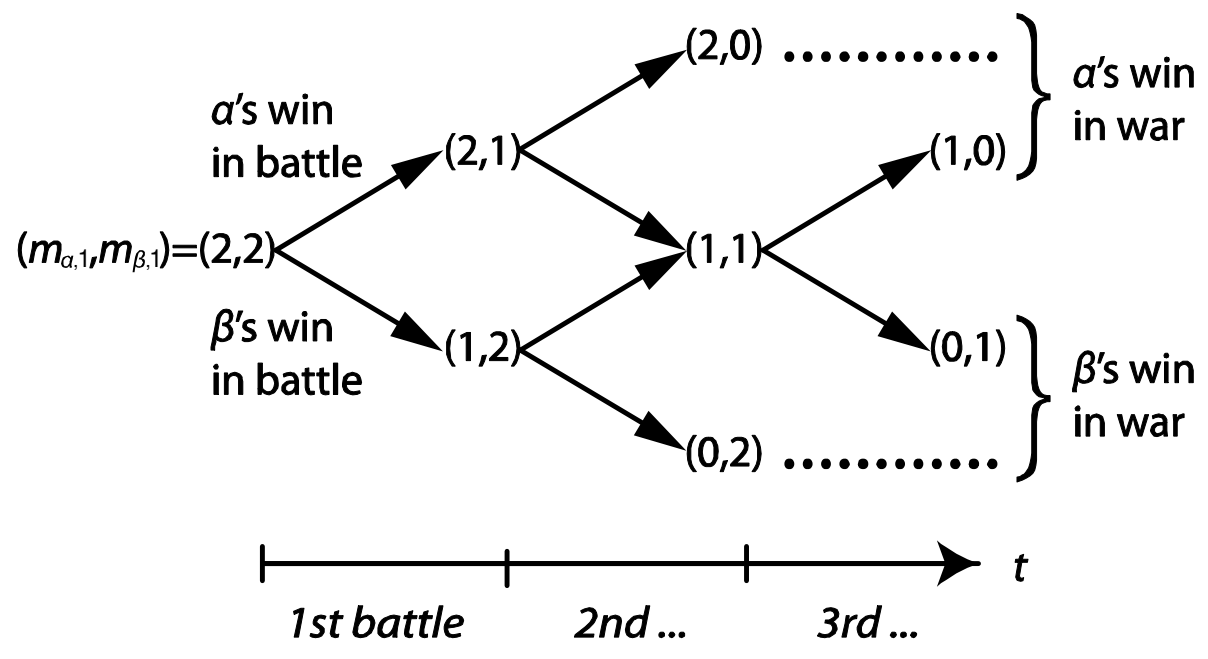

Figure 1: Flow of all-out war.

power. ${ }^{13}$ In each battle, $i$ 's "win" brings about his success in destroying one of $j$ 's military units $\left(m_{j, t+1}=m_{j, t}-1\right)$, and the war subsequently enters the next battle with the shifted military balance (i.e., $m_{i, t}$ against $m_{j, t}-1$ ). A denial by $i$ also inflicts a per-period cost $c^{D} \geq 0$ on $j$.

On the other hand, if $i$ adopts a punishment, he cannot "win" a battle but can impose a heavier cost $c_{m_{i, t}}^{P}$ on $j$. The size of $c_{m_{i, t}}^{P}$ depends on $i$ 's absolute strength $m_{i, t}-c_{m_{i, t}}^{P}$ increases with $m_{i, t}$-and is surely larger than $c^{D}$ (i.e., $c^{D}<c_{1}^{P}<c_{2}^{P}$ ). In addition, it is assumed that $c_{2}^{P}>2 c^{D}$, which substantially simplifies the analysis of equilibrium.

In the model, the pair of the belligerents' strength $\left(m_{\alpha, t}, m_{\beta, t}\right)$ functions as a state vector that affects the prospect of battles and hence of the war as a whole. The state vector $\left(m_{\alpha, t}, m_{\beta, t}\right)$ is essential for the analysis of the choice between denial and punishment on the ground that the distinction in the effectiveness between denial (determined by the relative strength) and punishment (by the absolute strength) is possible only with the state vector and would be impossible with a single state variable of the relative strength. ${ }^{14}$

The war (and also the game) end with $i$ 's victory when $j$ is fully disarmed $\left(m_{j, t}=\right.$

\footnotetext{
${ }^{13}$ Lanchester's power $L$ is interpreted as the degree of relative advantage to the stronger side (i.e., either $i$ with $m_{i, t}>m_{j, t}$ ) at the tactical/battle level.

${ }^{14}$ The single state variable is adopted by conventional bargaining models of war (Slantchev 2003b; Smith 1998; Smith and Stam 2003, 2004).
} 
0 ) or when $j$ surrenders $\left(\sigma_{j, t}=S\right)$. The former form of war is referred to as all-out war (Figure 1), while the latter form as limited war. If $i$ wins the war, $i$ seizes a lump-sum benefit $W>0$, while $j$ gains nothing. If both $i$ and $j$ surrender simultaneously, they both gain nothing. ${ }^{15}$

\subsection{Battles}

Depending on the belligerents' choices of targets $\left(\sigma_{\alpha}, \sigma_{\beta}\right)$ and their military capabilities $\left(m_{\alpha, t}, m_{\beta, t}\right)$, a battle results in one of $i$ 's "winning," "losing" and "indecisive" outcomes in a period. Presuming that the belligerents adopt stationary strategies, or that they maintain the same actions $\left(\sigma_{\alpha}, \sigma_{\beta}\right)$ as far as they are in the same state $\left(m_{\alpha, t}, m_{\beta, t}\right)$, we taxonomize the forms of battle:

Definition 1 (i) $A$ battle is called $\sigma_{\alpha}-\sigma_{\beta}$ battle $M_{t}$ (more shortly, $\sigma_{\alpha}-\sigma_{\beta}$ battle or battle $\left.M_{t}\right)$ if it is fought with action profile $\left(\sigma_{\alpha}, \sigma_{\beta}\right) \in\{D, P\}^{2}$ in state $M_{t} \in\{1,2\}^{2}$, where $M_{t} \equiv\left(m_{\alpha, t}, m_{\beta, t}\right)$. (ii) Of $\sigma_{\alpha}-\sigma_{\beta}$ battle $M_{t}$, $i$ 's "winning," "losing" and "indecisive" outcomes in a period are denoted as win $_{i \mid M_{t}}^{\sigma_{\alpha} \sigma_{\beta}}, \operatorname{los}_{i \mid M_{t}}^{\sigma_{\alpha} \sigma_{\beta}}$ and ind $d_{M_{t}}^{\sigma_{\alpha} \sigma_{\beta}}$, respectively.

In any battle, $i$ 's "win" is identical to $j$ 's "loss" (i.e., $\operatorname{win}_{i \mid M_{t}}^{\sigma_{\alpha} \sigma_{\beta}}=\operatorname{los}_{j \mid M_{t}}^{\sigma_{\alpha} \sigma_{\beta}}$ ). If a battle remains "indecisive" in a period, the same battle will be waged again in the next period.

For $D$ - $D$ battle $M_{t}$, per-period probabilities of the three outcomes are defined as:

$$
\begin{aligned}
\operatorname{Pr}\left(\text { win }_{\alpha \mid M_{t}}^{D D}\right) & =\frac{(1-\delta)\left(m_{\alpha, t}\right)^{L}}{\left(m_{\alpha, t}\right)^{L}+\left(m_{\beta, t}\right)^{L}} \\
\operatorname{Pr}\left(\text { win }_{\beta \mid M_{t}}^{D D}\right) & =\frac{(1-\delta)\left(m_{\beta, t}\right)^{L}}{\left(m_{\alpha, t}\right)^{L}+\left(m_{\beta, t}\right)^{L}} \\
\operatorname{Pr}\left(i n d_{M_{t}}^{D D}\right) & =\delta,
\end{aligned}
$$

\footnotetext{
${ }^{15}$ Trivially, it never happens in equilibrium that both belligerents simultaneously choose $S$, because either can be better off by choosing $D$ or $P$ instead of $S$.
} 
where $\delta \in(0,1) \cdot{ }^{16}$ In $P$ - $D$ battle, there is no possibility of $\alpha$ 's "win" - a punishment brings no victory. Instead, the battle is more likely to remain "indecisive":

$$
\begin{aligned}
\operatorname{Pr}\left(\operatorname{win}_{\alpha \mid M_{t}}^{P D}\right) & =0 \\
\operatorname{Pr}\left(\operatorname{win}_{\beta \mid M_{t}}^{P D}\right) & =\frac{(1-\delta)\left(m_{\beta, t}\right)^{L}}{\left(m_{\alpha, t}\right)^{L}+\left(m_{\beta, t}\right)^{L}} \\
\operatorname{Pr}\left(i n d_{M_{t}}^{P D}\right) & =\delta+\frac{(1-\delta)\left(m_{\alpha, t}\right)^{L}}{\left(m_{\alpha, t}\right)^{L}+\left(m_{\beta, t}\right)^{L}}
\end{aligned}
$$

Probabilities in $D-P$ battle are defined analogously. $P-P$ battle is won by neither; they merely hurt each other with no possibility of breaking forces (i.e., $\operatorname{Pr}\left(i n d_{M_{t}}^{P P}\right)=1$ ). The distribution of per-period probabilities in each form of $\sigma_{\alpha}-\sigma_{\beta}$ battle is summarized in Table 1.

Table 1: Per-period probabilities in each $\sigma_{\alpha}-\sigma_{\beta}$ battle.

\begin{tabular}{c|c|c|c} 
& $\operatorname{Pr}\left(\right.$ win $\left._{\alpha \mid M_{t}}^{\sigma_{\alpha} \sigma_{\beta}}\right)$ & $\operatorname{Pr}\left(i n d_{M_{t}}^{\sigma_{\alpha} \sigma_{\beta}}\right)$ & $\operatorname{Pr}\left(\right.$ win $\left._{\beta \mid M_{t}}^{\sigma_{\alpha} \sigma_{\beta}}\right)$ \\
\hline$D$ - $D$ battle & $\frac{(1-\delta)\left(m_{\alpha, t}\right)^{L}}{\left(m_{\alpha, t}\right)^{L}+\left(m_{\beta, t}\right)^{L}}$ & $\delta$ & $\frac{(1-\delta)\left(m_{\beta, t}\right)^{L}}{\left(m_{\alpha, t}\right)^{L}+\left(m_{\beta, t}\right)^{L}}$ \\
$D-P$ battle & $\frac{(1-\delta)\left(m_{\alpha, t}\right)^{L}}{\left(m_{\alpha, t}\right)^{L}+\left(m_{\beta, t}\right)^{L}}$ & $\delta+\frac{(1-\delta)\left(m_{\beta, t}\right)^{L}}{\left(m_{\alpha, t}\right)^{L}+\left(m_{\beta, t}\right)^{L}}$ & 0 \\
$P-D$ battle & 0 & $\delta+\frac{(1-\delta)\left(m_{\alpha, t}\right)^{L}}{\left(m_{\alpha, t}\right)^{L}+\left(m_{\beta, t}\right)^{L}}$ & $\frac{(1-\delta)\left(m_{\beta, t}\right)^{L}}{\left(m_{\alpha, t}\right)^{L}+\left(m_{\beta, t}\right)^{L}}$ \\
$P-P$ battle & 0 & 1 & 0
\end{tabular}

Unless both the belligerents choose $P$, $\alpha$ 's continuation payoff in $\sigma_{\alpha}-\sigma_{\beta}$ battle $M_{t}$ can be derived recursively:

$$
\begin{aligned}
U_{\alpha \mid M_{t}}^{\sigma_{\alpha} \sigma_{\beta}}= & \left.\operatorname{Pr}\left(\text { win }_{\alpha \mid M_{t}}^{\sigma_{\alpha} \sigma_{\beta}}\right) U_{\alpha \mid\left(m_{\alpha, t}, m_{\beta, t}-1\right)}^{*}+\operatorname{Pr}\left(\operatorname{los}_{\alpha \mid M_{t}}^{\sigma_{\alpha} \sigma_{\beta}}\right) U_{\alpha \mid\left(m_{\alpha, t}-1, m_{\beta, t}\right.}^{*}\right) \\
& +\operatorname{Pr}\left(i n d_{M_{t}}^{\sigma_{\alpha} \sigma_{\beta}}\right) U_{\alpha \mid M_{t}}^{\sigma_{\alpha} \sigma_{\beta}-c_{m_{\beta, t}}^{\sigma_{\beta}}} \\
= & \frac{\operatorname{Pr}\left(\text { win }_{\alpha \mid M_{t}}^{\sigma_{\alpha} \sigma_{\beta}}\right) U_{\alpha \mid\left(m_{\alpha, t}, m_{\beta, t}-1\right)}^{*}+\operatorname{Pr}\left(\operatorname{los}_{\alpha \mid M_{t}}^{\sigma_{\alpha} \sigma_{\beta}}\right) U_{\alpha \mid\left(m_{\alpha, t}-1, m_{\beta, t}\right)}^{*}-c_{m_{\beta, t}}^{\sigma_{\beta}}}{1-\operatorname{Pr}\left(i n d_{M_{t}}^{\sigma_{\alpha} \sigma_{\beta}}\right)},(1)
\end{aligned}
$$

where $U_{i \mid M_{t}}^{*}$ is $i$ 's continuation payoff in battle $M_{t}$ on the equilibrium path. Similarly, $\beta$ 's continuation payoff can be derived.

\footnotetext{
${ }^{16} \operatorname{Pr}\left(i n d_{M_{t}}^{\sigma_{\alpha} \sigma_{\beta}}\right)$ resembles but critically differs from the discount factor of conventional repeated games in that it varies depending on $\left(\sigma_{\alpha}, \sigma_{\beta}\right)$.
} 


\section{Equilibrium}

Focusing on stationary strategies, we adopt Markov Perfect Equilibrium as the solution of the game. Then each battle $M_{t}$ (with "surrender" as an outside option) can be simplified and represented in normal form (Table 2), and the war can be depicted as a game with three stages (Figure 1). After deriving equilibria in general battle $M_{t}$, we deliver the conditions for equilibria in specific battles by backward induction - from $(1,1)$ through $(2,1)$ and $(1,2)$ to $(2,2)$.

Table 2: Battle $M_{t}$ in normal form.

\begin{tabular}{c|c|c|c|}
\multicolumn{1}{c}{$\alpha \backslash \beta$} & \multicolumn{1}{c}{$D$} & $P$ & $S$ \\
\cline { 2 - 4 }$D$ & $U_{\alpha \mid M_{t}}^{D D}, U_{\beta \mid M_{t}}^{D D}$ & $U_{\alpha \mid M_{t}}^{D P}, U_{\beta \mid M_{t}}^{D P}$ & $W, 0$ \\
\cline { 2 - 4 }$P$ & $U_{\alpha \mid M_{t}}^{P D}, U_{\beta \mid M_{t}}^{P D}$ & $-\infty,-\infty$ & $W, 0$ \\
\cline { 2 - 4 }$S$ & $0, W$ & $0, W$ & 0,0 \\
\hline & & &
\end{tabular}

\subsection{Battle $M_{t}$ in General}

By the comparison of payoffs for each $i \in\{\alpha, \beta\}$ in Table 2, equilibria in battle $M_{t}$ can be determined.

Lemma 1 In any battle $M_{t}$, strategy profiles that can constitute an equilibrium are listed as follows:

(a) $(D, D)$ if $U_{\alpha \mid M_{t}}^{D D} \geq 0$ and $U_{\beta \mid M_{t}}^{D D} \geq 0$;

(b) $(D, S)$ if $U_{\beta \mid M_{t}}^{D D} \leq 0 ;\left(b^{\prime}\right)(S, D)$ if $U_{\alpha \mid M_{t}}^{D D} \leq 0$;

(c) $(P, S)$ if $U_{\beta \mid M_{t}}^{P D} \leq 0 ;\left(c^{\prime}\right)(S, P)$ if $U_{\alpha \mid M_{t}}^{D P} \leq 0$;

(d) $\left(\sigma^{D P}, S\right)$ if $U_{\beta \mid M_{t}}^{D D} \leq 0$ and $U_{\beta \mid M_{t}}^{P D} \leq 0$, where $\sigma^{D P}$ can be any mixed strategy that contains $D$ and/or $P ;^{17}\left(d^{\prime}\right)\left(S, \sigma^{D P}\right)$ if $U_{\alpha \mid M_{t}}^{D D} \leq 0$ and $U_{\alpha \mid M_{t}}^{D P} \leq 0$;

(e) $\left(\sigma_{\alpha \mid M_{t}}^{D S}, \sigma_{\beta \mid M_{t}}^{D S}\right)$ if $U_{\alpha \mid M_{t}}^{D D}<0$ and $U_{\beta \mid M_{t}}^{D D}<0$, where $\sigma_{\alpha \mid M_{t}}^{D S}\left(\sigma_{\beta \mid M_{t}}^{D S}\right)$ is $\alpha$ 's ( $\beta$ 's) mixed strategy that randomly takes $D$ and $S$ such that $U_{\beta \mid M_{t}}^{\sigma_{\alpha S}^{D S} D}=0\left(U_{\alpha \mid M_{t}}^{D \sigma_{\beta \mid M_{t}}^{D S}}=0\right)$.

\footnotetext{
${ }^{17} \sigma^{D P}$ can be purely $D$ or $P$.
} 
Among the equilibria in Lemma $1,(D, D)$ regards the battle as a costly lottery (Reiter 2003; Wagner 2000), so that the repetition of $D$ - $D$ battles resembles to random-walk models of war (Smith 1998; Smith and Stam 2003, 2004), which depict war as a series of battles with unpredictable outcomes. Other equilibria correspond to those in the war-of-attrition model, where either player surrenders immediately, or both players surrender probabilistically.

Lemma 1 will be utilized to find equilibria in each specific battle. 


\subsection{Specific Battles}

In any battle $M_{t}$, a belligerent's rational decision depends on the size of booty $W$ relative to the costs $c^{D}$ and $c_{m_{i, t}}^{P}$. If $W$ is sufficiently large, both the belligerents are willing to choose denial; otherwise, either side may surrender.

Proposition 1 In battle $(1,1)$, all equilibria are:

(i) $(D, D)$ for $W \in\left(W_{3 r d}^{P}, \infty\right)$;

(ii) $(D, D),(P, S)$, and $(S, P)$ for $W \in\left(W_{3 r d}^{D}, W_{3 r d}^{P}\right]$;

$(i i)$ ) $(D, D),\left(\sigma^{D P}, S\right)$, and $\left(S, \sigma^{D P}\right)$ for $W=W_{3 r d}^{D}$;

(iii) $\left(\sigma^{D P}, S\right),\left(S, \sigma^{D P}\right)$, and $\left(\sigma_{\alpha \mid(1,1)}^{D S}, \sigma_{\beta \mid(1,1)}^{D S}\right)$ for $W \in\left(0, W_{3 r d}^{D}\right)$, where

$$
\begin{aligned}
W_{3 r d}^{P} & \equiv \frac{2 c_{1}^{P}}{1-\delta} \\
W_{3 r d}^{D} & \equiv \frac{2 c^{D}}{1-\delta}
\end{aligned}
$$

Proof. As Lemma 1 shows, the equilibria depend on the signs of $U_{\alpha \mid M_{t}}^{D D}, U_{\beta \mid M_{t}}^{D D}, U_{\alpha \mid M_{t}}^{D P}$ and $U_{\beta \mid M_{t}}^{P D}$. By Equation (1),

$$
\begin{aligned}
& U_{\alpha \mid(1,1)}^{D D}=U_{\beta \mid(1,1)}^{D D}=\frac{W}{2}-\frac{c^{D}}{1-\delta} \\
& U_{\alpha \mid(1,1)}^{D P}=U_{\beta \mid(1,1)}^{P D}=W-\frac{2 c_{1}^{P}}{1-\delta}
\end{aligned}
$$

Accordingly, $U_{\alpha \mid(1,1)}^{D D} \gtreqless 0$ if $W \gtreqless W_{3 r d}^{D}$, and $U_{\alpha \mid(1,1)}^{D P} \leq 0$ if $W \leq W_{3 r d}^{P}$.

By Lemma 1, equilibria in battle $(1,1)$ are listed as: (a) $(D, D)$ if $W \geq W_{3 r d}^{D}$; (b, b') $(D, S)$ and $(S, D)$ if $W \leq W_{3 r d}^{D}$; (c, c') $(P, S)$ and $(S, P)$ if $W \leq W_{3 r d}^{P}$; (d, d') $\left(\sigma^{D P}, S\right)$ and $\left(S, \sigma^{D P}\right)$ if $W \leq W_{3 r d}^{D}$ and $W \leq W_{3 r d}^{P} ;(\mathrm{e})\left(\sigma_{\alpha \mid(1,1)}^{D S}, \sigma_{\beta \mid(1,1)}^{D S}\right)$ if $W<W_{3 r d}^{D}$. Because $c^{D}<c_{1}^{P}, W_{3 r d}^{D}<W_{3 r d}^{P}$, with which the equilibria can be summarized as in the proposition.

Proposition 1 is summarized graphically in Figure 2. If $W$ is not so large, multiple equilibria emerge where the belligerents may not fight. ${ }^{18}$ To rule out these uninteresting "no-fight" equilibria in battle $(1,1)$, we impose the following restriction:

\footnotetext{
${ }^{18}$ If they do not fight in battle $(1,1)$, neither would they fight in battle $(2,2)$, because a war starting with $D$ - $D$ battle $(2,2)$ is longer and thus more costly than $D$ - $D$ battle $(1,1)$.
} 


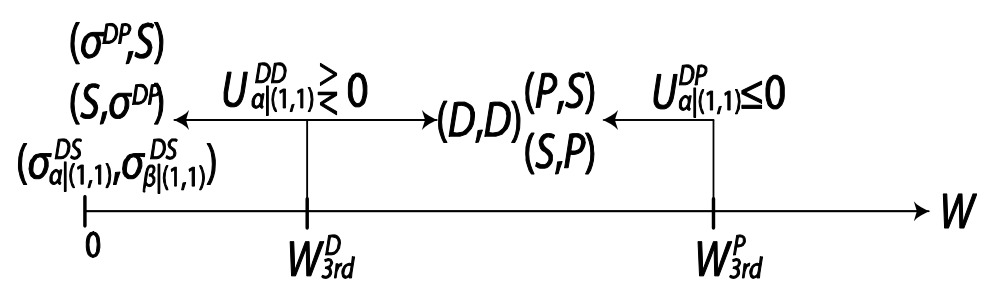

Figure 2: Equilibria in battle $(1,1)$.

Assumption $1 W>W_{3 r d}^{P}$.

By making $(D, D)$ the unique equilibrium in battle $(1,1)$, Assumption 1 greatly simplifies the analysis of battles $(2,1)$ and $(1,2)$.

Proposition 2 In battle $(2,1)$, all equilibria are:

(i) $(D, D)$ for $W \in\left(W_{2 n d}^{P}, \infty\right)$;

(ii) $(D, D)$ and $(P, S)$ for $W \in\left(\max \left\{W_{3 r d}^{P}, W_{2 n d}^{D}\right\}, W_{2 n d}^{P}\right]$;

in addition, if $W_{3 r d}^{P}<W_{2 n d}^{D}$, they are:

(ii') $(D, D)$ and $\left(\sigma^{D P}, S\right)$ for $W=W_{2 n d}^{D}$;

(iii) $\left(\sigma^{D P}, S\right)$ for $W \in\left(W_{3 r d}^{P}, W_{2 n d}^{D}\right)$, where

$$
\begin{aligned}
W_{2 n d}^{P} & \equiv \frac{2 c^{D}+\left(2^{L+1}+2\right) c_{2}^{P}}{1-\delta} \\
W_{2 n d}^{D} & \equiv\left(2^{L+1}+4\right) \frac{c^{D}}{1-\delta} .
\end{aligned}
$$

Trivially, equilibria in battle $(1,2)$ are identical to those in $(2,1)$ except that the players swap sides, because the game is symmetric with respect to them. ${ }^{19}$ Proposition 2 then implies that the stronger side (e.g., $\alpha$ in $(2,1)$ ) never surrenders in the second battles. ${ }^{20}$ It also holds that the war may proceed along one of the two major paths. ${ }^{21}$ In one, say the path of "fight even with a single arm," where if the booty is sufficiently large $\left(W \geq W_{2 n d}^{D}\right)$, the belligerents fight $D$ - $D$ battles $(2,1)$ and $(1,2)$ - the weaker side is willing to fight even a disadvantageous battle. In the other path of "no fight

\footnotetext{
${ }^{19}$ Equilibria in battle $(1,2)$ are: $(D, D),(S, P)$ instead of $(P, S)$, and $\left(S, \sigma^{D P}\right)$ instead of $\left(\sigma^{D P}, S\right)$ with the corresponding conditions in Proposition 2.

${ }^{20}$ This claim appears as Lemma 3 in Appendix.

${ }^{21}$ We ignore the asymmetric (and implausible) paths, where $D$ - $D$ battle is waged only in either $(2,1)$ or $(1,2)$.
} 
with a single arm" (with $W \leq W_{2 n d}^{P}$ ), the weaker side surrenders in battles $(2,1)$ and $(1,2)$. The latter path is plausible if the stronger side is tactically so advantageous (with a large $L$ ) and/or if the damage by punishment is so heavy (with a large $\left.c_{2}^{P}\right)$. As Proposition 2-(ii, iii) reads that $(P, S)$ holds more broadly than $\left(\sigma^{D P}, S\right)$, punishment has greater coercive effects than denial $\left(W_{2 n d}^{D}<W_{2 n d}^{P}\right)$. In addition, punishment functions as a "knockout punch" in the sense that the weaker belligerent immediately gives in once it is threatened with punishment.

Below we focus on the former path (of "fight even with a single arm") in battle $(2,2)$, because battle $(2,2)$ in the latter path is identical to $(1,1)$.

Proposition 3 In battle $(2,2)$ followed by $D$-D battles $(2,1)$ and $(1,2)$, all equilibria are:

(i) $(D, D)$ for $W \in\left(W_{1 s t}^{P}, \infty\right)$;

(ii) $(D, D),(P, S)$, and $(S, P)$ for $W \in\left(\max \left\{W_{3 r d}^{P}, W_{1 s t}^{D}\right\}, W_{1 s t}^{P}\right]$;

in addition, if $W_{3 r d}^{P}<W_{1 s t}^{D}$, they are:

$\left.(i i)^{\prime}\right)(D, D),\left(\sigma^{D P}, S\right)$, and $\left(S, \sigma^{D P}\right)$ for $W=W_{1 s t}^{D}$;

(iii) $\left(\sigma^{D P}, S\right),\left(S, \sigma^{D P}\right)$, and $\left(\sigma_{\alpha \mid(2,2)}^{D S}, \sigma_{\beta \mid(2,2)}^{D S}\right)$ for $W \in\left(W_{3 r d}^{P}, W_{1 s t}^{D}\right)$, where

$$
\begin{aligned}
& W_{1 s t}^{P} \equiv \frac{\left(2^{L+1}+4\right) c^{D}+\left(2^{L+2}+4\right) c_{2}^{P}}{\left(2^{L+1}+1\right)(1-\delta)} \\
& W_{1 s t}^{D} \equiv \frac{\left(2^{L+2}+6\right) c^{D}}{\left(2^{L}+1\right)(1-\delta)} .
\end{aligned}
$$

Among the equilibria in Proposition 3, $(D, D)$ may depict a war with conventional weapons - conventional wars start with exchange of denials, because a punishment has limited effectiveness (with a small $\left.c_{2}^{P}\right)$. In contrast, $(P, S)$ and $(S, P)$ may represent a class of nuclear wars where the threat by a preemptive punishment can compel the targeted state to immediately surrender. In $\left(\sigma^{D P}, S\right)$ and $\left(S, \sigma^{D P}\right)$, the booty $(W)$ is so small that the state yields even to a preemptive denial.

Since our interests are in conventional wars, we impose the following restriction:

Assumption $2 W>W_{1 s t}^{P}$.

With Assumption 2, the war starts with $D$ - $D$ battle $(2,2)$. 

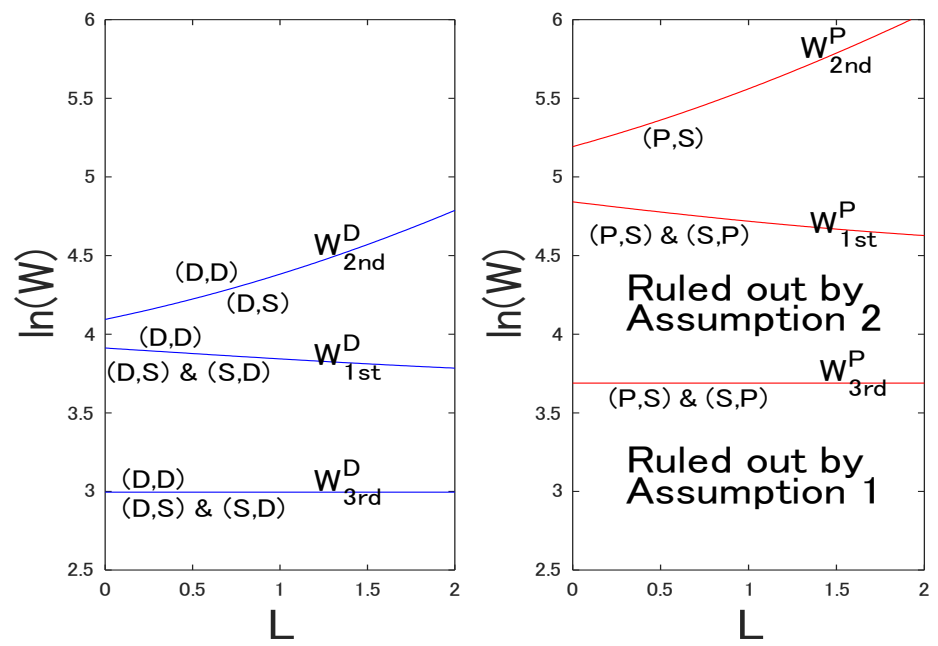

Figure 3: Thresholds that demarcate equilibria in three stages.

\subsection{Dynamic of Target Choice in War}

Utilizing the equilibrium outcomes in each of the three stages above, we next explore the patterns of target choice in war. The dynamic of target choice in war is shaped by the transition of the coerciveness of denial and punishment, or the relative sizes of the thresholds that demarcate equilibria in each of the three stages $\left(W_{3 r d}^{\sigma}, W_{2 n d}^{\sigma}\right.$, and $W_{1 s t}^{\sigma}$ for $\sigma \in\{D, P\}$ defined in respective Propositions 1, 2 and 3). These thresholds have the following relationships: ${ }^{22}$

Lemma 2 Both denial and punishment have the most coercive power in the second battle; i.e., regardless of $L$,

$$
W_{3 r d}^{\sigma}<W_{1 s t}^{\sigma}<W_{2 n d}^{\sigma} \text { for each } \sigma \in\{D, P\}
$$

The relationships among these thresholds determine how the war evolves:

Proposition 4 For $W \in\left(W_{2 n d}^{D}, W_{2 n d}^{P}\right)$, the entire game has the following two equilibria: (i) denials are exchanged in all battles; (ii) denials are exchanged in battle $(2,2)$, whose winner initiates punishment, and the loser gives in. ${ }^{23}$

\footnotetext{
${ }^{22}$ The thresholds of $W$ (with logarithms) are graphed in Figure 3 , given $c^{D}=\frac{1}{2}, c_{1}^{P}=1, c_{2}^{P}=2$, and $\delta=0.95$.

${ }^{23}$ For $W>W_{2 n d}^{P}$, the exchange of denials is the unique equilibrium in all battles (Proposition
} 
Proof. In battles $(1,1)$ and $(2,2),(D, D)$ is the unique equilibrium (Assumptions 1 and 2$)$. In battle $(2,1)$, only $(D, D)$ and $(P, S)$ can be an equilibrium for $W \in$ $\left(W_{2 n d}^{D}, W_{2 n d}^{P}\right)$ (Proposition 2-(ii)). In addition, since $W_{1 s t}^{P}<W_{2 n d}^{P}$ (Lemma 2), there exists a range of $W$ such that $W_{1 s t}^{P}<W<W_{2 n d}^{P}$. (Recall that Assumption 2 rules out $\left.W \leq W_{1 s t}^{P}\right)$

Proposition 4 implies that the war evolves in one of the two paths (Table 3): allout war, where denials are exchanged throughout ("fight even with a single arm" in battles $(2,1)$ and $(1,2))$; limited war, which ends with the weaker side's surrender ("no fight with a single arm"). In the latter path, a belligerent who refuses to surrender at the war's onset may yield to punishment once he loses the first battle-punishment has more coercive power if the targeted belligerent is disadvantageous.

Table 3: Two equilibrium paths.

\begin{tabular}{c|c|c|c} 
& $\begin{array}{c}\text { 1st battle } \\
(2,2)\end{array}$ & $\begin{array}{c}\text { 2nd battles } \\
(2,1) \&(1,2)\end{array}$ & $\begin{array}{c}\text { 3rd battle } \\
(1,1)\end{array}$ \\
\hline All-out war & $(D, D)$ & $(D, D)$ & $(D, D)$ \\
\hline Limited war & $(D, D)$ & $\begin{array}{c}(P, S) \text { in }(2,1) \\
(S, P) \text { in }(1,2)\end{array}$ & $\begin{array}{c}(D, D) \\
\text { off equilibrium }\end{array}$
\end{tabular}

The limited-war equilibrium may offer a novel reason for why denials often precede punishments in conventional wars. As far as the belligerents are evenly matched, punishment cannot coerce the targeted belligerent into surrender. Without the possibility of surrender, a punishment merely wastes the opportunity of denial to weaken the opponent. Thus exertion of punishment in the early stage of war disadvantages the attacker himself in future battles. Only after the attacker overpowers the other, can punishment become coercive. This result may explain why belligerents do not resort to punishment at a war's onset.

The current model contains two problems: (1) multiple equilibria can still remain in battles $(2,1)$ and $(1,2)$ (when $W \in\left(W_{2 n d}^{D}, W_{2 n d}^{P}\right)$ ), suggesting that the model fails

2-(i)). For $W<W_{2 n d}^{D}$, the loser of battle $(2,2)$ succumbs even to the winner's denial (Proposition 2-(iii)). However, a limited war ending with denial is not so plausible as the one ending with punishment, because in battle $(2,1),(P, S)$ can be an equilibrium whenever $(D, S)$ is (Proposition 2 -(ii, iii) - punishment has greater coercive power than denial $\left(W_{2 n d}^{D}<W_{2 n d}^{P}\right)$. 
to predict whether the war is all-out or limited (Proposition 2-(ii, ii')) ${ }^{24}$ (2) it also fails to explain why punishment lasted so long as it did in past conventional wars. In the limited-war equilibrium, once the stronger side initiates punishment, the other side immediately gives in. This pattern evidently contradicts some past wars during which civilians were targeted persistently (e.g., the Pacific War).

These two problems can be resolved in light of growing risk associated with punishment, which we explore next.

\footnotetext{
${ }^{24}$ Another possibility to resolve the multiplicity of equilibrium is to make the choices sequentialone party makes his decision earlier than the other in a battle. One may do so by demonstrating his commitment to a certain campaign. In battle $(2,1), \alpha$, who prefers $(P, S)$ to $(D, D)$, may commit himself to punishment, while $\beta$, for whom $(D, D)$ is preferred, may try to be stuck to denial. An instance of the former would be the U.S. strategic bombings on Japanese cities during the Pacific War - the U.S. repeatedly demonstrated its resolve for punishment by warning Japan of the bombings while summoning it to surrender (Zacharias' radio broadcast). A well-known instance of the latter is the Battle of Jingxing (in China, 205 BC), where general Han Xin banned retreat by positioning his army back to the water - a tactic known as "burning bridges" (Schelling 1966: 43-49).
} 


\section{$5 \quad$ Risk Strategy}

To incorporate prolonged punishment, we introduce uncertainty with the severity of punishment. For punishment to last for certain periods, the targeted belligerent's incentive must shift from choosing $D$ to $S$ over time. Built upon the idea of the risk strategy (Pape 1996: 66-69; Schelling 1966: 105-109), we consider one of such scenarios. The solution concept for the modified game will be Perfect Bayesian Equilibrium.

Suppose that each belligerent is either hard or soft type $\left(i \in\left\{i^{h}, i^{s}\right\}\right)$. By a punishment with $m_{i, t}=2$, the hard type $i^{h}$ inflicts a severer damage $c^{h}$ on $j$ with perperiod probability $\varepsilon^{h} \in[0,1)$ and the regular damage $c_{2}^{P}$ with remaining probability $1-\varepsilon^{h}$, while the soft type $i^{s}$ inflicts a milder damage $c^{s}$ with probability $\varepsilon^{s} \in(0,1)$ and $c_{2}^{P}$ with remaining probability $1-\varepsilon^{s} \cdot{ }^{25}$ It is naturally assumed that $c_{1}^{P} \leq c^{s}<$ $c_{2}^{P}<c^{h}{ }^{26}$ Targeted $j$ does not know whether $i$ is hard or soft at the war's onset, but he knows $i$ 's prior distribution $\operatorname{Pr}\left(i^{h}\right)$ and $\operatorname{Pr}\left(i^{s}\right)$, where $\operatorname{Pr}\left(i^{h}\right)+\operatorname{Pr}\left(i^{s}\right)=1$.

As $i$ conducts punishments, $j$ can infer $i$ 's type from precipitated damages. By Bayes' rule, the damage $c^{h}\left(c^{s}\right)$ reveals $i=i^{h}\left(i=i^{s}\right)$ for sure: $\operatorname{Pr}\left(i^{h} \mid c^{h}\right)=1$ and $\operatorname{Pr}\left(i^{s} \mid c^{s}\right)=1$. Also, if $j$ bears $T$ times of $c_{2}^{P}$ in succession, he updates his belief as to $i^{h}$ :

$$
\begin{aligned}
\operatorname{Pr}\left(i^{h} \mid T\right) & =\frac{\operatorname{Pr}\left(i^{h}\right) \operatorname{Pr}\left(c_{2}^{P} \mid i^{h}\right)^{T}}{\operatorname{Pr}\left(i^{h}\right) \operatorname{Pr}\left(c_{2}^{P} \mid i^{h}\right)^{T}+\operatorname{Pr}\left(i^{s}\right) \operatorname{Pr}\left(c_{2}^{P} \mid i^{s}\right)^{T}} \\
& =\frac{1}{1+\frac{\operatorname{Pr}\left(i^{s}\right)}{\operatorname{Pr}\left(i^{h}\right)}\left(\frac{1-\varepsilon^{s}}{1-\varepsilon^{h}}\right)^{T}} .
\end{aligned}
$$

If $\varepsilon^{h}<\varepsilon^{s}, \operatorname{Pr}\left(i^{h} \mid T\right)$ increases with $T$, or the risk of the severer damage $c^{h}$ grows over time, and we assume so.

A merit of modifying the effectiveness of punishment instead of denial is tractability it affects equilibria in battles $(2,1)$ and $(1,2)$, while maintaining $(D, D)$ as the unique equilibrium in $(1,1)$ and $(2,2)$ if $W$ is sufficiently large. ${ }^{27}$ Below we focus on battle

\footnotetext{
${ }^{25}$ The model can work even with $\varepsilon^{h}=0$ as far as $\varepsilon^{s} \in(0,1)$.

${ }^{26}$ The irregular damage $c^{h}\left(c^{s}\right)$ may represent the attacker's advancement of weaponry (tightening of military budget).

${ }^{27}$ In battle $(1,1)$, because there is no uncertainty with $c_{1}^{P}$, the equilibrium is uniquely $(D, D)$ by Assumption 1. In battle $(2,2)$, the condition for $(D, D)$ to be the unique equilibrium is formally derived in Appendix. Alternatively, if denial has uncertain effectiveness, belligerents' behavior in all three stage games must be re-calculated, and thus the resulting equilibrium analysis would be much more complicated.
} 
$(2,1)$, but the following analysis applies symmetrically to $(1,2)$.

Consider the following strategy profile $\left(P, P^{\prime}, T^{*}\right)$ : (a) $\alpha^{h}$ maintains $P$ throughout the battle; (a') $\alpha^{s}$ maintains $P$ and switches to $D$ if $c^{s}$ occurs; (b) $\beta$ maintains $D$ and switches to $S$ if $c^{h}$ occurs or if $c_{2}^{P}$ occurs $T^{*}$ times successively. If $c^{s}$ occurs, $\beta$ maintains $D$ forever.

Given strategy profile $\left(P, P^{\prime}, T\right)$, continuation payoffs of $\alpha^{h}$ and $\alpha^{s}$ can be defined as:

$$
\begin{aligned}
U_{\alpha^{h} \mid(2,1)}^{P T} \equiv \operatorname{Pr}\left(i n d_{\alpha^{h} \mid(2,1)}^{P D}\right)^{T} W+\frac{1-\operatorname{Pr}\left(i n d_{\alpha^{h} \mid(2,1)}^{P D}\right)^{T}}{1-\operatorname{Pr}\left(i n d_{\alpha^{h} \mid(2,1)}^{P D}\right)}\left(\begin{array}{c}
\operatorname{Pr}\left(i n d_{(2,1)}^{P D}\right) \varepsilon^{h} W+ \\
\operatorname{Pr}\left(\operatorname{los}_{\alpha \mid(2,1)}^{P D}\right) U_{\alpha \mid(1,1)}^{D D}-c^{D}
\end{array}\right) \\
U_{\alpha^{s} \mid(2,1)}^{P^{\prime} T} \equiv \operatorname{Pr}\left(i n d_{\alpha^{s} \mid(2,1)}^{P^{\prime} D}\right)^{T} W+\frac{1-\operatorname{Pr}\left(i n d_{\alpha^{s} \mid(2,1)}^{P^{\prime} D}\right)^{T}}{1-\operatorname{Pr}\left(i n d_{\alpha^{s} \mid(2,1)}^{P^{\prime} D}\right)}\left(\begin{array}{c}
\operatorname{Pr}\left(i n d_{(2,1)}^{P D}\right) \varepsilon^{s} U_{\alpha \mid(2,1)}^{D D}+ \\
\operatorname{Pr}\left(\operatorname{los} \operatorname{los}_{\alpha \mid(2,1)}^{P D}\right) U_{\alpha \mid(1,1)}^{D D}-c^{D}
\end{array}\right),
\end{aligned}
$$

where

$$
\begin{aligned}
& \operatorname{Pr}\left(i n d_{\alpha^{h} \mid(2,1)}^{P D}\right) \equiv \operatorname{Pr}\left(i n d_{(2,1)}^{P D}\right)\left(1-\varepsilon^{h}\right) \\
& \operatorname{Pr}\left(i n d_{\alpha^{s} \mid(2,1)}^{P^{\prime} D}\right) \equiv \operatorname{Pr}\left(i n d_{(2,1)}^{P D}\right)\left(1-\varepsilon^{s}\right) .
\end{aligned}
$$

On the other hand, $\beta$ 's continuation payoff after $T$ times of $c_{2}^{P}$ can be shown as:

$$
U_{\beta \mid(2,1)}^{P P^{\prime} D}(T) \equiv \operatorname{Pr}\left(\alpha^{h} \mid T\right) U_{\beta|(2,1)| \alpha^{h}}^{P D}+\operatorname{Pr}\left(\alpha^{s} \mid T\right) U_{\beta|(2,1)| \alpha^{s}}^{P^{\prime} D}
$$

where $U_{\beta|(2,1)| \alpha^{h}}^{P D}$ and $U_{\beta|(2,1)| \alpha^{s}}^{P^{\prime} D}$ are $\beta$ 's continuation payoffs from choosing $D$ against $\alpha^{h}$ 's $P$ and against $\alpha^{s}$ 's $P^{\prime}$, respectively:

$$
\begin{aligned}
U_{\beta|(2,1)| \alpha^{h}}^{P D} & \equiv \frac{\operatorname{Pr}\left(\operatorname{win}_{\beta \mid(2,1)}^{P D}\right) U_{\beta \mid(1,1)}^{D D}-\left(1-\varepsilon^{h}\right) c_{2}^{P}-\varepsilon^{h} c^{h}}{1-\operatorname{Pr}\left(i n d_{\alpha^{h} \mid(2,1)}^{P D}\right)} \\
U_{\beta|(2,1)| \alpha^{s}}^{P^{\prime} D} & \equiv \frac{\operatorname{Pr}\left(\operatorname{win}_{\beta \mid(2,1)}^{P D}\right) U_{\beta \mid(1,1)}^{D D}+\operatorname{Pr}\left(i n d_{(2,1)}^{P D}\right) \varepsilon^{s} U_{\beta \mid(2,1)}^{D D}-\left(1-\varepsilon^{s}\right) c_{2}^{P}-\varepsilon^{s} c^{s}}{1-\operatorname{Pr}\left(i n d_{\alpha^{s} \mid(2,1)}^{P^{\prime} D}\right)} .
\end{aligned}
$$

For $\beta$ 's learning to be meaningful and influence his behavior, $\beta$ should be willing to fight the soft type but not the hard one: 
Assumption 3 (i) $U_{\beta|(2,1)| \alpha^{h}}^{P D}<0$. (ii) $U_{\beta|(2,1)| \alpha^{s}}^{P^{\prime} D}>0$.

If there is no uncertainty, equilibria $(D, D)$ and $(P, S)$ coexist in battle $(2,1)$ for $W \in\left(W_{2 n d}^{D}, W_{2 n d}^{P}\right)$ (Proposition 2-(ii)). However, once the uncertainty is introduced, $(D, D)$ and $(P, S)$ become out of equilibrium, and instead $\left(P, P^{\prime}, T^{*}\right)$ appears as an equilibrium if the players' incentive compatibility constraints are met:

Proposition 5 (i) For $W \in\left(W_{2 n d}^{D}, W_{2 n d}^{P}\right)$, the strategy profile $\left(P, P^{\prime}, T^{*}\right)$ forms an equilibrium in battle $(2,1)$ if: (a) $U_{\alpha^{h} \mid(2,1)}^{P T^{*}} \geq U_{\alpha \mid(2,1)}^{D D}$; (a') $U_{\alpha^{s} \mid(2,1)}^{P^{\prime} T^{*}} \geq U_{\alpha \mid(2,1)}^{D D}$; (b) $U_{\beta \mid(2,1)}^{P P^{\prime} D}(\varnothing) \geq 0$. (ii) $T^{*}$ is the smallest $T$ such that $U_{\beta \mid(2,1)}^{P P^{\prime} D}(T)<0 .{ }^{28}$

Proof. (i) By Conditions (a, a'), $\alpha^{h}\left(\alpha^{s}\right)$ is willing to choose $P\left(P^{\prime}\right)$ against $\beta$ 's $T^{*}$. By (b), which requires Assumption 3-(ii), $\beta$ is willing to fight at least for one period. If $c^{h}$ occurs, $\beta$ will surrender, because of Assumption 3-(i) with $\operatorname{Pr}\left(\alpha^{h} \mid c^{h}\right)=1$. Similarly, because of Assumption 3-(ii) with $\operatorname{Pr}\left(\alpha^{s} \mid c^{s}\right)=1$, if $c^{s}$ occurs, $\beta$ will maintain $D$ forever. Moreover, knowing that $\beta$ maintains $D$ forever, $\alpha^{s}$ switches to $D$, because $W \in\left(W_{2 n d}^{D}, W_{2 n d}^{P}\right)$.

(ii) With $\varepsilon^{h}<\varepsilon^{s}$, as $T$ rises, $\operatorname{Pr}\left(i^{h} \mid T\right)$ increases, and $U_{\beta \mid(2,1)}^{P P^{\prime} D}(T)$ decreases. With a sufficiently large $T, \operatorname{Pr}\left(i^{h} \mid T\right)$ converges to one, and $U_{\beta \mid(2,1)}^{P^{\prime} D}(T)$ does to $U_{\beta|(2,1)| \alpha^{h}}^{P D}$. Since $U_{\beta|(2,1)| \alpha^{h}}^{P D}<0$ (Assumption 3-(i)), there must exist $T$ such that $U_{\beta \mid(2,1)}^{P P^{\prime} D}(T)<0$, with which $\beta$ switches from $D$ to $S$.

In light of the risk strategy, $\beta$ does not immediately yield to $\alpha$ 's punishment. Through fighting, $\beta$ speculates on $\alpha$ 's type with hope for winning. Upon a critical punishment $\left(c^{h}\right), \beta$ immediately gives in, but otherwise $\beta$ holds out for a while. Hence, punishment can persist for certain periods in battle $(2,1)$.

To look over the series of the battles, the model with uncertainty proceeds as follows: the war breaks out with exchange of denials in battle $(2,2)$. As $\alpha$ wins battle $(2,2)$, he initiates punishment in battle $(2,1)$. If $\alpha$ succeeds in punishment (with $c^{h}$ or $T^{*}$ times of $c_{2}^{P}$ ), the war ends with $\beta^{\prime}$ s surrender. If $\alpha$ fails, the war goes back to the exchange of denials. The model depicts the transition from mutual denials to persistent punishments by the winning side, as observed in the Pacific War.

\footnotetext{
${ }^{28}$ The existence of this equilibrium is conditional critically on the prior distribution $\operatorname{Pr}\left(i^{h}\right)$ and $\operatorname{Pr}\left(i^{s}\right)$ - while $\alpha^{h}$ 's $\left(\alpha^{s}\right.$ 's) choice of $P\left(P^{\prime}\right)$ depends on the timing $T^{*}$ of $\beta$ 's surrender, $T^{*}$ depends on the priors. With larger $\operatorname{Pr}\left(i^{s}\right), T^{*}$ would be larger, and the incentive for $\alpha^{h}\left(\alpha^{s}\right)$ to choose $P$ $\left(P^{\prime}\right)$ weaker. The size of $T^{*}$ depends also on the likelihood ratio $\frac{1-\varepsilon^{s}}{1-\varepsilon^{h}}$, which determines the speed

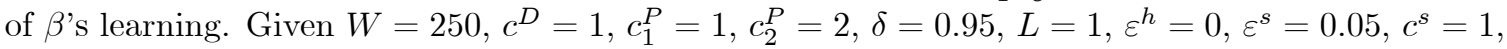
and $\operatorname{Pr}\left(i^{s}\right)=0.25$, then $\left(P, P^{\prime}, T^{*}\right)$ emerges as the unique equilibrium with $T^{*}=7$.
} 


\section{The Pacific War: From Mutual Denials to One- Sided Punishments}

The Pacific War was waged in ways our theory predicts: (i) denials were exchanged at the early stage; (ii) punishments were adopted by the winning side (the U.S.) toward the end; (iii) no or little punishments were taken by the losing side (Japan) throughout. ${ }^{29}$

In the War (that broke out in December 1941), the U.S. accomplished overwhelming victories at the critical battles of Midway (in June 1942), Philippine Sea (in June 1944), and Leyte Gulf (in October 1944). Since the summer of 1944 when Japan lost the Mariana Islands (the Absolute Zone of National Defense of 1943), the U.S. military victory had become evident. However, despite successive losses in battles and the resulting serious shortage of military resources, Japan continued to prosecute the War. The U.S. then introduced a series of punishment campaigns, including "carpet" bombings on cities (from March 1945), "starvation" blockades on ports (from March 1945), and finally nuclear attacks on Hiroshima and Nagasaki (in August 1945). Only after the U.S. succeeded in these punishment campaigns, did Japan declare to surrender.

The reasons why Japan surrendered have been disputed among historians. While "orthodox" historians have maintained the atomic bombings as the major cause of Japan's surrender (Asada 1998; Feis 1961; Frank 1999; Freedman and Dockrill 1994), the so-called "revisionists" and their sympathizers have put more emphasis on the Soviet entry into the War (Alperovitz 1985, 1995; Bernstein 1995, 2007; Hasegawa 2005, 2007; Pape 1993). The former account corresponds to a realization of $c^{h}$ in our model, while the latter does to a sudden rise in $m_{\alpha}$ (where $\alpha$ denotes the Union). Our theory suggests that it might be inadequate to attribute Japan's surrenderespecially when it surrendered - solely to its either military or civilian vulnerability. Even when a punishment seems to work, it does so only because of preceding denials that have made punishment effectively coercive. Denial and punishment may operate differently in shaping a war.

\footnotetext{
${ }^{29}$ Air raids on Oregon (in September 1942) and fire ballons (from November 1944) might be few exceptions that represent Japan's attempts at punishment.
} 


\section{Conclusion}

\subsection{Theoretical Findings}

This article urges readers to heed an agenda that the theoretical literature has overlooked - the dilemma between force ("guns") and value ("butter") as targets of attacks in war. Under what kind of circumstances, which campaign better serves the purposes of war between (counterforce) denial and (countervalue) punishment? How do these choices shape war? One of our model's novelties is that it allows belligerents to flexibly change their targets during war. This flexibility in targeting enables to depict the two-way causal relationship between military strategies and war that existing studies have ruled out - in one way, the belligerents' choices of targets determine how the war evolves; in the other, past battles (both their outcomes and duration) influence their choices in upcoming battles.

Through equilibrium analyses, we have produced the following theoretical findings. Unless punishments are so destructive as nuclear bombings, belligerents initiate war with an exchange of denial campaigns, which consequently brings about a military imbalance in favor of the winner of the early battle (precisely, $D-D$ battle $(2,2)$ ). The war then proceeds along one of the two paths (namely, two equilibria): one is of all-out war, where the belligerents continue to exchange denial campaigns until either side is fully disarmed; the other of limited war, where the winner of the early battle switches to punishment campaign ("knockout punch"), to which the loser responds by capitulation. Along either path, the belligerents refrain from punishment in the early stage of war, because punishment has no or little coercive effect on an opponent with equal or similar strength. In other words, the coerciveness of punishment depends on the relative military balance, but this balance is determined by the exchange of denials. Only after the opponent is sufficiently weakened by denial, can punishment have a coercive effect. Our theory thus holds that denials precede punishments in limited war (Arreguín-Toft 2001: 108-109; Downes 2008: 115-155; Legro 1995). This pattern resembles MacNamara's "no city" doctrine of 1962 that refrains from attacks on cities, but the reason we offered above is different from his doctrine's that aims to keep civilians as "hostages" (Long 2008:30). ${ }^{30}$

\footnotetext{
${ }^{30}$ There can be other reasons for why denials precede punishments: (i) air superiority with technological and geographical constraints - before engaging aerial bombardment against distant cities, the attacker needs to secure the air superiority (Pape 1996: 58); (ii) diminishing effectiveness of denial-
} 
The discussion above contains two drawbacks: (1) in light of the two equilibria, the model cannot conclude which is more plausible between all-out and limited wars; (2) the immediate capitulation in response to punishment in limited war contradicts patterns of some past wars, where punitive bombings persisted durably (e.g., the Pacific War). These drawbacks can be overcome once Schelling's (1966: 105-109) risk strategy is introduced. With this extension, the two equilibria can be replaced by a single equilibrium, where the exchange of denials is followed by the prevailing side's prolonged punishment. ${ }^{31}$

To draw implications for air strategies, one of our major findings consorts with Pape's (1996) assertion that denial constitutes a primary determinant of war's outcome, while punishment has little impact on it. When the prevailing side initiates punishment, the tide of war has already been determined. ${ }^{32}$ Another implication drawn from our model is that punishment can shorten a war by charging the targeted belligerent with extra burden of continuing the war. ${ }^{33}$ In sum, denials largely determine war's outcome (which side to win), while punishments can influence its duration (when to surrender). The Pacific War conforms to our theoretical predictions.

\subsection{Implications toward Empirical Studies}

Our findings above cast some concerns toward empirical procedures in existing studies. Assuming that each belligerent chooses a single military strategy at a war's onset

as the targeted enemy loses its forces in battles, it can become harder for an attacker to achieve additional tactical success; (iii) reciprocity and its breakup-belligerents may refrain from countervalue campaigns as far as their enemies also refrain (for WWI, Axelrod 1984: 77-87; for WWII, Legro 1995), but this reciprocal relationship can collapse once either side loses its capabilities of "punishment."

${ }^{31}$ Out of the two equilibria, the stronger side $(\alpha$ in battle $(2,1))$ prefers limited war, while the weaker side prefers all-out war. Introduction of the risk strategy favors the stronger side - the risk strategy can pull off the victory by punishment as in limited war.

${ }^{32}$ The loser of $D-D$ battle $(2,2)$ has little chance to make a recovery and win the war. This claim holds even if the loss of strength in battle $(2,2)$ does not cause disadvantage in later battles (i.e., $L=0)$. Even with $L=0$, the probability that $\beta$ wins both $D$ - $D$ battles $(2,1)$ and $(1,1)$ in all-out war is $(1 / 2)^{2}=1 / 4$. The probability can be even smaller with $L>0$ and furthurmore with the risk strategy.

${ }^{33}$ The war's duration depends critically on how quickly the targeted belligerent learns about the attacker's capability of punishment (i.e., $1-\varepsilon^{s} / 1-\varepsilon^{h}$ ). Prolonged punishment may also stem from three other possibilities: (i) as a persistent punishment accumulates damages, the per-period cost suffered by the targeted belligerent increases over time; (ii) it takes time for the targeted belligerent to produce the decision of surrender (e.g., toward the end of the Pacific War, the Japanse leadership could not produce the decision of surrender until the Emperor finally intervened); (iii) the threshold of the surrender decision falls over time (Bennett and Stam 1998). 
and adheres to it throughout, most of the existing studies have abstracted away the possibility that belligerents' choices of strategies are influenced by the ongoing war's battles. $^{34}$ Put differently, when the existing studies analyzed the effects of military strategies on war, they treated military strategies as explanatory variables and categorized war's outbreak, duration and outcome as dependent variables. However, if the effectiveness of a certain military strategy changes during a war, it is quite plausible that the belligerents condition their choices of strategies on how the war was waged. ${ }^{35}$ That is, past battles of the ongoing war itself can influence the choice of military strategy, while military strategies shape how the war will further evolve. If battles' outcomes and duration do have such causal effects on military strategies, a certain strategy might be adopted only in particular circumstances (i.e., the selection effect).

For instance, if punishment is undertaken only by the side which has fought advantageously and is almost winning a war, it cannot be concluded that punishment is an effective strategy to bring about victory (Reiter and Stam 1998, 2002; Stam 1996: 138). Conversely, it is rather the advantageous military imbalance that prompted belligerents to adopt punishment. Other studies determined punishment to be ineffective (Horowitz and Reiter 2001; Pape 1996), but it seems so merely because these analyses included punishments used in wrong timing and situation. ${ }^{36}$ As our theory holds, punishment is not particularly coercive on its own, but it can be made coercive by successful denial - punishment can be effective but only conditionally. Analogously, the seemingly causal finding that punishment tends to make a war longer (Bennett and Stam 1996) contradicts our prediction that punishment can shorten a war if the punisher has overpowered the opponent. As a way to reconcile this contradiction, it could be inferred that punishment is more likely to be employed in prolonged wars. ${ }^{37}$

\footnotetext{
${ }^{34}$ To be fair, at least some scholars have acknowledged the effect of battle outcome on military strategy and consciously ruled it out of their analyses (Stam 1996: 192-193).

${ }^{35}$ In this regard, our theory suggests that there exists no such thing as "dominant" military strategy - a strategy that is unconditionally optimal - that some scholars contend (Biddle 2004; Stam 1996: 89, 145-147).

${ }^{36}$ German bombings on British cities in WWII could be regarded as Hitler's irrational reaction to British bombings on Berlin.

${ }^{37}$ Another possible source of this contradiction is the presumption that guerrilla and countercivilian airstrike have the same impacts and are grouped in the same category of punishment despite their distinct characteristics (Bennett and Stam 1996; Reiter and Meek 1999; Stam 1996; Wallace 2008). Although missing in the literature on military strategy, a starvation blockade can also form punishment (for WWI, Downes 2008: 83-114; for the U.S. Operation Starvation in the Pacific War, Frank 1999: 349-360; Pape 1993, 1996: 98-103).
} 


\subsection{Erosion of Legal and Moral Constraints during War}

Finally, we close our discussion with the implications toward international laws. Our theory casts a grave concern toward the compliance with international laws that prohibit or restrict attacks on civilians (e.g., Hague IV, IX; Rules of Air Warfare; Geneva IV, Protocol I; Convention on Certain Conventional Weapons Protocol III). As our theory predicts, even if a belligerent is unwilling to attack civilian targets at war's onset, it would be tempted to resort to counter-civilian campaigns to ensure its own victory once it obtains military advantage especially toward the end of war. This prediction suggests that state leadership may have different mind sets and incentives for counter-civilian campaigns in peace time than in war (Downes 2008: 115-155). In this regard, jus in bello may suffer the commitment problem (Biddle online) besides the conventional enforcement problem caused by the anarchic nature of world politics. Massive records on war crimes in past wars conform to this concern- some international laws that aimed to regulate belligerents' behavior were very often neglected once wars broke out. In fact, it was Franklin Roosevelt who proposed on the eve of WWII that the belligerents refrain from air bombings on civilian populations and unfortified cities. In response, Neville Chamberlain and Adolf Hitler agreed with Roosevelt's appeal (Legro 1995: 99). However, as the War escalated to the full scale, all Britain, Germany, and the U.S. adopted air bombings on cities as if there were no such agreement (Kennett 1982: 106). The development of international agreements, norms and laws that can discipline warring states requires the imagination of how a war pressures state leaders in every scenario. An undertaking to such legal and institutional arrangements will presumably remain a very hard challenge. 


\section{APPENDIX}

Proof of Lemma 1. Among the nine pure-strategy profiles in Table 2, only $(D, D),(D, S),(S, D),(P, S)$, and $(S, P)$ can be an equilibrium, leaving no possibility of equilibrium for other pure-strategy profiles. $(P, D)$ cannot be an equilibrium, because $U_{\alpha \mid M_{t}}^{D D}>U_{\alpha \mid M_{t}}^{P D}$. This inequality always holds, since $\operatorname{Pr}\left(\right.$ win $\left._{\alpha \mid M_{t}}^{P D}\right)=0$ (namely, $\alpha$ cannot "win" a battle by choosing $P$ ) and $\operatorname{Pr}\left(i n d_{M_{t}}^{P D}\right)>\operatorname{Pr}\left(i n d_{M_{t}}^{D D}\right)$ (for $\alpha$, a battle against $\beta$ 's $D$ is longer and more costly with $P$ than with $D)$. For the same reason, $(D, P)$ cannot be an equilibrium. Trivially, neither $(P, P)$ nor $(S, S)$ can be an equilibrium.

For (a, b, b'), each $i$ 's best response against $j$ 's $D$ is $D$ if $U_{i \mid M_{t}}^{D D} \geq 0$ and $S$ if $U_{i \mid M_{t}}^{D D} \leq 0$.

For (c, c'), $(P, S)$ can be an equilibrium if $U_{\beta \mid M_{t}}^{P D} \leq 0$ (or if $\beta$ prefers $S$ to $D$ against $\alpha$ 's $P)$; similarly, $(S, P)$ can be if $U_{\alpha \mid M_{t}}^{D P} \leq 0$.

For (d, d') that combine (b, b') and (c, c'), if $j$ chooses $S, i$ gains $W$ by $D, P$, or any strategy that mixes them.

For (e), in an equilibrium where both players randomize their strategies, each player must be indifferent between the actions he takes with positive probabilities. If $U_{\beta \mid M_{t}}^{D D}<0$ and $U_{\alpha \mid M_{t}}^{D D}<0$, there exists $\left(\sigma_{\alpha \mid M_{t}}^{D S}, \sigma_{\beta \mid M_{t}}^{D S}\right)$ such that $U_{\beta \mid M_{t}}^{\sigma_{\alpha S}^{D S} D}=0$ and $U_{\alpha \mid M_{t}}^{D \sigma_{\beta \mid M_{t}}^{D S}}=0$, or that $\alpha$ and $\beta$ are indifferent between $D$ and $S$. In addition, because each $i$ prefers $D$ to $P$ against $j$ 's $D$ or $P$ (in fact, $D$ weakly dominates $P$ ), no mixedstrategy equilibrium (other than those in (d, d') where either $i$ chooses $S$ for sure) can contain $P$ with a positive probability. If $P$ cannot be contained, the only possible mixed-strategy equilibrium is $\left(\sigma_{\alpha \mid M_{t}}^{D S}, \sigma_{\beta \mid M_{t}}^{D S}\right)$.

Lemma 3 In battle $(2,1)$, there exists no equilibrium where $\alpha$ surrenders.

Proof. As with Proposition 1, $\alpha$ 's decision depends on the signs of $U_{\alpha \mid(2,1)}^{D D}$ and $U_{\alpha \mid(2,1)}^{D P}$. By Equation (1) with $U_{i \mid(1,1)}^{*}=U_{i \mid(1,1)}^{D D}$ (the equilibrium of battle $(1,1)$ is only $(D, D)$ by Assumption 1),

$$
\begin{aligned}
U_{\alpha \mid(2,1)}^{D D} & =\frac{2^{L}+\frac{1}{2}}{2^{L}+1} W-\frac{2^{L}+2}{2^{L}+1} \frac{c^{D}}{1-\delta} \\
U_{\alpha \mid(2,1)}^{D P} & =W-\frac{2^{L}+1}{2^{L}} \frac{c_{1}^{P}}{1-\delta},
\end{aligned}
$$


both of which are positive, or $W>\max \left\{\frac{\left(2^{L+1}+4\right) c^{D}}{\left(2^{L+1}+1\right)(1-\delta)}, \frac{\left(2^{L}+1\right) c_{1}^{P}}{2^{L}(1-\delta)}\right\}$ by Assumption 1 (recall $\left.c^{D}<c_{1}^{P}\right)$. Therefore, none of $(S, D),(S, P),\left(S, \sigma^{D P}\right)$ and $\left(\sigma_{\alpha \mid M_{t}}^{D S}, \sigma_{\beta \mid M_{t}}^{D S}\right)$ in Lemma 1 can be an equilibrium of battle $(2,1)$.

Proof of Proposition 2. This proof is also based on Lemma 1. Since $U_{\alpha \mid(2,1)}^{D D}>0$ and $U_{\alpha \mid(2,1)}^{D P}>0$ by Lemma 3 , equilibria in battle $(2,1)$ depend on the signs of $U_{\beta \mid(2,1)}^{D D}$ and $U_{\beta \mid(2,1)}^{P D}$, which are:

$$
\begin{aligned}
U_{\beta \mid(2,1)}^{D D} & =\frac{1}{2^{L}+1} \frac{W}{2}-\frac{2^{L}+2}{2^{L}+1} \frac{c^{D}}{1-\delta} \\
U_{\beta \mid(2,1)}^{P D} & =\frac{W}{2}-\frac{c^{D}+\left(2^{L}+1\right) c_{2}^{P}}{1-\delta}
\end{aligned}
$$

by Equation (1). Hence, $U_{\beta \mid(2,1)}^{D D} \gtreqless 0$ if $W \gtreqless W_{2 n d}^{D}$, and $U_{\beta \mid(2,1)}^{P D} \leq 0$ if $W \leq W_{2 n d}^{P}$, where $W_{2 n d}^{D}<W_{2 n d}^{P}$ regardless of $L$. Because $W>W_{3 r d}^{P}$ (Assumption 1), equilibria in (ii', iii) are non-existent if $W_{2 n d}^{D}<W_{3 r d}^{P}$.

Proof of Proposition 3. The proof also relies on Lemma 1. By Equation (1) with $U_{\alpha \mid(2,1)}^{*}=U_{\beta \mid(1,2)}^{*}=U_{\alpha \mid(2,1)}^{D D}$ and $U_{\beta \mid(2,1)}^{*}=U_{\alpha \mid(1,2)}^{*}=U_{\beta \mid(2,1)}^{D D}$,

$$
\begin{aligned}
& U_{\alpha \mid(2,2)}^{D D}=U_{\beta \mid(2,2)}^{D D}=\frac{1}{2} W-\frac{2^{L+1}+3}{2^{L}+1} \frac{c^{D}}{1-\delta} \\
& U_{\alpha \mid(2,2)}^{D P}=U_{\beta \mid(2,2)}^{P D}=\frac{2^{L}+\frac{1}{2}}{2^{L}+1} W-\frac{\left(2^{L}+2\right) c^{D}+\left(2^{L+1}+2\right) c_{2}^{P}}{\left(2^{L}+1\right)(1-\delta)}
\end{aligned}
$$

The signs of them determine the equilibria: $U_{\alpha \mid(2,2)}^{D D} \gtreqless 0$ if $W \gtreqless W_{1 s t}^{D} ; U_{\alpha \mid(2,2)}^{D P} \leq 0$ if $W \leq W_{1 s t}^{P}$, where $W_{1 s t}^{D}<W_{1 s t}^{P}$ regardless of $L$, because $c_{2}^{P}>2 c^{D}$.

Proof of Lemma 2. The proof compares $W_{1 s t}^{\sigma}, W_{2 n d}^{\sigma}$, and $W_{3 r d}^{\sigma}$ for each $\sigma \in\{D, P\}$. When $L=0$,

$$
\begin{array}{lll}
W_{1 s t}^{D}=\frac{5 c^{D}}{1-\delta}, & W_{2 n d}^{D}=\frac{6 c^{D}}{1-\delta}, & W_{3 r d}^{D}=\frac{2 c^{D}}{1-\delta}, \\
W_{1 s t}^{P}=\frac{2 c^{D}+\frac{8}{3} c_{2}^{P}}{1-\delta}, & W_{2 n d}^{P}=\frac{2 c^{D}+4 c_{2}^{P}}{1-\delta}, & W_{3 r d}^{P}=\frac{2 c_{1}^{P}}{1-\delta},
\end{array}
$$

ensuring that $W_{3 r d}^{\sigma}<W_{1 s t}^{\sigma}<W_{2 n d}^{\sigma}$ for each $\sigma \in\{D, P\}$ with $L=0$. As $L$ increases, $W_{1 s t}^{D}\left(W_{1 s t}^{P}\right)$ decreases and converges to $\frac{4 c^{D}}{1-\delta}\left(\frac{2 c^{D}+2 c_{2}^{P}}{1-\delta}\right), W_{2 n d}^{D}\left(W_{2 n d}^{P}\right)$ increases, and $W_{3 r d}^{D}\left(W_{3 r d}^{P}\right)$ remains constant. Thus, their relative sizes are maintained even if $L$ 
increases.

\section{Equilibrium Condition for $(\mathbf{D}, \mathbf{D})$ in Battle $(2,2)$ with the Risk Strategy}

In battle $(2,2),(D, D)$ forms the unique equilibrium if each type of $i$ is willing to choose $D$ regardless of $j$ 's type and strategy, or if for $\alpha \in\left\{\alpha^{h}, \alpha^{s}\right\}$ and $\beta \in\left\{\beta^{h}, \beta^{s}\right\}$,

$$
\begin{aligned}
& U_{\alpha|(2,2)| \beta}^{D D} \equiv \frac{U_{\alpha \mid(2,1)}^{P P^{\prime} T^{*}}}{2}+\frac{U_{\alpha \mid(1,2)}^{T^{*} P P^{\prime}}(\varnothing)}{2}-\frac{c^{D}}{1-\delta}>0 \\
& U_{\alpha|(2,2)| \beta}^{D P} \equiv U_{\alpha \mid(2,1)}^{P P^{\prime} T^{*}}-2 \frac{(1-\varepsilon) c_{2}^{P}+\varepsilon c}{1-\delta}>0,
\end{aligned}
$$

where $U_{\alpha \mid(1,2)}^{T^{*} P P^{\prime}}(\varnothing)=U_{\beta \mid(2,1)}^{P P^{\prime} T^{*}}(\varnothing)$ (in Equality $(2)$ ), while $\varepsilon=\varepsilon^{h}\left(\varepsilon^{s}\right)$ and $c=c^{h}\left(c^{s}\right)$ for $\beta=\beta^{h}\left(\beta^{s}\right)$. (By $U_{\alpha|(2,2)| \beta}^{\sigma_{\alpha} \sigma_{\beta}}$, both types of $\alpha(\beta)$ choose $\sigma_{\alpha}\left(\sigma_{\beta}\right)$.) These conditions indicate that $\alpha$ is willing to choose $D$ against denial or punishment by $\beta \in\left\{\beta^{h}, \beta^{s}\right\}$. Because $(D, D)$ is pooling, no learning of the types is possible. 


\section{References}

[1] Alperovitz, Gar. 1985. Atomic Diplomacy, Hiroshima and Potsdam: The Use of the Atomic Bomb and the American Confrontation with Soviet Power. New York: Penguin Books.

[2] Alperovitz, Gar. 1995. The Decision to Use the Atomic Bomb and the Architecture of an American Myth. New York: Alfred A. Knopf.

[3] Arreguín-Toft, Ivan. 2001. "How the Weak Win Wars: A Theory of Asymmetric Conflict." International Security. 26(1): 93-128.

[4] Asada, Sadao. 1998. "The Shock of the Atomic Bomb and Japan's Decision to Surrender: A Reconsideration." Pacific Historical Review. 67(4): 477-512.

[5] Axelrod, Robert.1984. The Evolution of Cooperation. New York: Basic Books.

[6] Ball, Desmond. 1983. Targeting for Strategic Deterrence. London: International Institute for Strategic Studies.

[7] Bellany, Ian. 1999. "Modelling War." Journal of Peace Research. 36(6): 729-739.

[8] Belkin, Aaron, Michael Clark, Gulriz Gokcek, Robert Hinckley, Thomas Knecht, and Eric Patterson. 2000. "When Is Strategic Bombing Effective? Domestic Legitimacy and Aerial Denial." Security Studies. 11(4): 51-88.

[9] Bennett, D. Scott, and Allan C. Stam III. 1996. "The Duration of Interstate Wars, 1816-1985." American Political Science Review. 90(2): 239-257.

[10] Bennett, D. Scott, and Allan C. Stam III. 1998. "The Declining Advantages of Democracy: A Combined Model of War Outcomes and Duration." Journal of Conflict Resolution. 42(3): 344-366.

[11] Bernstein, Barton J. 1995. "The Atomic Bombings Reconsidered." Foreign Affairs. 74(1): 135-152.

[12] Bernstein, Barton J. 2007. "Introducing the Interpretive Problems of Japan's 1945 Surrender: A Historiographical Essay on Recent Literature in the West." In: Tsuyoshi Hasegawa. ed. The End of the Pacific War: Reappraisals. Stanford, CA: Stanford University Press, 9-64. 
[13] Biddle, Stephen. 2004. Military Power: Explaining Victory and Defeat in Modern Battle. Princeton, NJ: Princeton University Press.

[14] Biddle, Tami Davis. 1995. "British and American Approaches to Strategic Bombings: Their Origins and Implementation in the World War II Combined Bomber Offensive." Journal of Strategic Studies. 18(1): 91-144.

[15] Biddle, Tami Davis. 2002. Rhetoric and Reality in Air Warfare: The Evolution of British and American Ideas about Strategic Bombing, 1914-1945. Princeton, NJ: Princeton University Press.

[16] Biddle, Tami Davis. [online]. "Views on the Morality of Bombing." At $<$ http://ww2history.com/experts/Tami_Biddle/Views_on_the_morality_of_bombing $>$ accessed on February 26, 2017.

[17] Bier, Vicki, Santiago Oliveros, and Larry Samuelson. 2007. "Choosing What to Protect: Strategic Defensive Allocation against an Unknown Attacker." Journal of Public Economic Theory. 9(4): 1-25.

[18] Borel, Emile. 1921. "La théorie de jeu et les équations intégrales à noyau symétique." Comptes Rendus de l'Académie des Sciences. 173: 1304-1308. English Translation by Leonard J. Savage. 1953. "The Theory of Play and Integral Equations with Skew Symmetric Kernels." Econometrica. 21(1): 97-100.

[19] Brown, Michael E., Owen R. Coté Jr., Sean M. Lynn-Jones, and Steven E. Miller, ed. 2004. Offense, Defense, and War. Cambridge, MA: MIT Press.

[20] Carr, Caleb. 2003. The Lessons of Terror: A History of Warfare against Civilians. New York: Random House.

[21] Caverley, Jonathan D. 2010/11. "Explaining U.S. Military Strategy in Vietnam: Thinking Clearly about Causation." International Security. 35(3): 124-143.

[22] Clausewitz, Carl von. [1832] 1976. On War. Princeton, NJ: Princeton University Press.

[23] Douhet, Giulio. [1921] 1983. The Command of the Air. Washington D.C.: Office of Air Force History. 
[24] Downes, Alexander B. 2008. Targeting Civilians in War. Ithaca, NY: Cornell University Press.

[25] Echevarria II, Antulio J. 2017. Military Strategy: A Very Short Introduction. New York: Oxford University Press.

[26] Epstein, Joshua M. 1987. Strategy and Force Planning: The Case of the Persian Gulf. Washington D.C.: Prookings Institution.

[27] Fearon, James D. 2004. "Why Do Some Civil Wars Last So Much Longer Than Others?" Journal of Peace Research. 41(3): 275-301.

[28] Fearon, James D. 2007. "Fighting rather than Bargaining." Paper presented at the 2007 Annual Meetings of the American Political Science Association, Chicago, August 30-September 2, 2007.

[29] Feis, Herbert. 1961. Japan Subdued: The Atomic Bomb at the End of the War in the Pacific. Princeton, NJ: Princeton University Press.

[30] Filson, Darren, and Suzanne Werner. 2002. "A Bargaining Model of War and Peace: Anticipating the Onset, Duration, and Outcome of War." American Journal of Political Science. 46(4): 819-837.

[31] Filson, Darren, and Suzanne Werner. 2004. "Bargaining and Fighting: The Impact of Regime Type on War Onset, Duration, and Outcome." American Journal of Political Science. 48(2): 296-313.

[32] Frank, Richard. 1999. Downfall: The End of the Imperial Japanese Empire. New York: Penguin Books.

[33] Freedman, Lawrence. 2003. The Evolution of Nuclear Strategy. 3rd edition. New York: Palgrave Macmillan.

[34] Freedman, Lawrence, and Saki Dockrill. 1994. "Hiroshima: A Strategy of Shock." In: Saki Dockrill ed. From Pearl Harbor to Hiroshima: The Second World War in Asia and the Pacific, 1941-1945. New York: Palgrave Macmillan, 191-212.

[35] Goemans, H. E. 2000. War and Punishment: The Causes of War Termination $\&$ the First World War. Princeton, NJ: Princeton University Press. 
[36] Golman, Russell, and Scott E. Page. 2009. "General Blotto: Games of Allocative Strategic Mismatch." Public Choice. 138(3/4): 279-299.

[37] Hart, Sergiu. 2008. "Discrete Colonel Blotto and General Lotto Games." International Journal of Game Theory. 36(3): 441-460.

[38] Hasegawa, Tsuyoshi. 2005. Racing the Enemy: Stalin, Truman, and the Surrender of Japan. Cambridge, MA: Harvard University Press.

[39] Hasegawa, Tsuyoshi. 2007. "The Atomic Bombs and the Soviet Invasion: Which Was More Important in Japan's Decision to Surrender?" In: Tsuyoshi Hasegawa. ed. The End of the Pacific War: Reappraisals. Stanford, CA: Stanford University Press, 111-144.

[40] Horowitz, Michael, and Dan Reiter. 2001. "When Does Aerial Bombing Work?: Quantitative Empirical Tests, 1917-1999" Journal of Conflict Resolution. 45(2): 147-173.

[41] Johnston, Patrick B., and Anoop K. Sarbahi. 2016. "The Impact of US Drone Strikes on Terrorism in Pakistan." International Studies Quarterly. 60(2): 203219.

[42] Kennett, Lee. 1982. A History of Strategic Bombing: From the First Hot-Air Balloons to Hiroshima and Nagasaki. New York: Charles Scribner's Sons.

[43] Kocher, Mattew Adam, Thomas B. Pepinsky, and Stathis N. Kalyvas. 2011. "Aerial Bombing and Counterinsurgency in the Vietnam War." American Journal of Political Science. 55(2): 201-218.

[44] Lanchester, Frederick William. [1916] 2009. Aircraft in Warfare: The Dawn of the Forth Arm. Whitefish, MT. Kessinger Publishing.

[45] Lambeth, Benjamin S. 2000. The Transformation of American Air Power. Ithaca, NY: Cornell University Press.

[46] Langlois, Jean-Pierre P., and Catherine C. Langlois. 2009. "Does Attrition Behavior Help Explain the Duration of Interstate Wars? A Game Theoretic and Empirical Analysis." International Studies Quarterly. 53(4): 1051-1073. 
[47] Langlois, Jean-Pierre P., and Catherine C. Langlois. 2012. "Does the Principle of Convergence Really Hold? War, Uncertainty and the Failure of Bargaining." British Journal of Political Science. 42(3): 511-536.

[48] Legro, Jeffrey W. 1995. Cooperation under Fire: Anglo-German Restraint during World War II. Ithaca, NY: Cornell University Press.

[49] Leventoğlu, Bahar, and Branislav L. Slantchev 2007. "The Armed Peace: A Punctuated Equilibrium Theory of War." American Journal of Political Science. 51(4): 755-771.

[50] Liddell-Hart, Basil Henry. [1967] 1991. Strategy. 2nd ed. New York: Penguin Books.

[51] Lindsey, David. 2015. "Military Strategy, Private Information, and War." International Studies Quarterly. 59(4): 629-640.

[52] Long, Austin. 2008. Deterrence From Cold War to Long War. Lessons from Six Decades of RAND Research. Santa Monica, CA: RAND Corporation.

[53] Lyall, Jason. 2009. "Does Indiscriminate Violence Incite Insurgent Attacks? Evidence from Chechnya." Journal of Conflict Resolution. 53(3): 331-362.

[54] MacIsaac, David. 1986. "Voices from the Central Blue: The Air Power Theorists." In: Peter Paret. ed. Makers of Modern Strategy: from Machiavelli to the Nuclear Age. Princeton, NJ: Princeton University Press, 624-647.

[55] Maynard Smith, John. 1974. "Theory of Games and the Evolution of Animal Conflicts." Journal of Theoretical Biology. 47(1): 209-221.

[56] Mearsheimer, John J. 1983. Conventional Deterrence. Ithaca, NY: Cornell University Press.

[57] Mueller, Karl. 1998. "Strategies of Coercion: Denial, Punishment, and the Future of Air Power." Security Studies. 7(3): 182-228.

[58] Pape, Robert A. 1993. "Why Japan Surrendered." International Security. 18(2): 154-201. 
[59] Pape, Robert A. 1996. Bombing to Win: Air Power and Coercion in War. Ithaca, NY: Cornell University Press.

[60] Powell, Robert. 2004a. "The Inefficient Use of Power: Costly Conflict with Complete Information." American Political Science Review. 98(2): 231-241.

[61] Powell, Robert. 2004b. "Bargaining and Learning While Fighting." American Journal of Political Science. 48(2): 344-361.

[62] Powell, Robert. 2007a. "Defending against Terrorist Attacks with Limited Resources." American Political Science Review. 101(3): 527-541.

[63] Powell, Robert. 2007b. "Allocating Defensive Resources with Private Information about Vulnerability." American Political Science Review. 101(4): 799-809.

[64] Powell, Robert. 2009. "Sequential, Non-Zero-Sum 'Blotto': Allocating Defensive Resources Prior to Attack." Games and Economic Behavior. 67(2): 611-615.

[65] Powell, Robert. 2012. "Persistent Fighting and Shifting Power. " American Journal of Political Science. 56(3): 620-637.

[66] Reiter, Dan. 1999. "Military Strategy and the Outbreak of International Conflict." Journal of Conflict Resolution. 43(3): 366-387.

[67] Reiter, Dan. 2003. "Exploring the Bargaining Model of War." Perspectives on Politics. 1(1): 27-43.

[68] Reiter, Dan, and Curtis Meek. 1999. "Determinants of Military Strategy, 19031994: A Quantitative Empirical Test." International Studies Quarterly. 43(2): $363-387$.

[69] Reiter, Dan, and Allan C. Stam III. 1998. "Democracy and Battlefield Military Effectiveness." Journal of Conflict Resolution. 42(3): 259-277.

[70] Reiter, Dan, and Allan C. Stam III. 2002. Democracies at War. Princeton, NJ: Princeton University Press.

[71] Roberson, Brian. 2006. "The Colonel Blotto Game." Economic Theory. 29(1): 1-24. 
[72] Roberson, Brian, and Dmitriy Kvasov. 2012. "The Non-Constant-Sum Colonel Blotto Game." Economic Theory. 51(2): 397-433.

[73] Schelling, Thomas C. 1966. Arms and Influence. New Haven, CT: Yale University Press.

[74] Slantchev, Branislav L. 2003a. "The Power to Hurt: Costly Conflict with Completely Informed States." American Political Science Review. 97(1): 123-133.

[75] Slantchev, Branislav L. 2003b. "The Principle of Convergence in Wartime Negotiation." American Political Science Review. 97(4): 621-32.

[76] Slantchev, Branislav. 2010. "Feigning Weakness." International Organization. 64(3): $357-388$.

[77] Smith, Alastair. 1998. "Fighting Battles, Winning Wars." Journal of Conflict Resolution. 42(3): 301-320.

[78] Smith, Alastair, and Allan C. Stam. 2003. "Mediation and Peacekeeping in a Random Walk Model of Civil and Interstate War." International Studies Review. 5(4): 115-135.

[79] Smith, Alastair, and Allan C. Stam. 2004. "Bargaining and the Nature of War." Journal of Conflict Resolution. 48(6): 783-813.

[80] Stam III, Allan C. 1996. Win, Lose, or Draw: Domestic Politics and the Crucible of War. Ann Arbor, MI: University of Michigan Press.

[81] Tarar, Ahmer. 2016. "A Strategic Logic of the Military Fait Accompli." International Studies Quarterly. 60(4): 742-752.

[82] Toft, Monica Duffy, and Yuri M. Zhukov. 2012. "Denial and Punishment in the North Caucasus: Evaluating the Effectiveness of Coercive Counter-Insurgency." Journal of Peace Research. 49(6): 785-800.

[83] Wagner, Harrison R. 2000. "Bargaining and War." American Journal of Political Science. 44(3): 469-84.

[84] Wallace, Geoffrey P. R. 2008. "Alliances, Institutional Design, and Determinants of Military Strategy." Conflict Management and Peace Science. 25(3): 224-243. 
[85] Wang, Chen, and Vicki M. Bier. 2011. "Target-Hardening Decisions Based on Uncertain Multiattribute Terrorist Utility." Decision Analysis. 8(4): 286-302.

[86] Warden, John A. III. 1997. "Success in Modern War: A Response to Robert Pape's Bombing to Win." Security Studies. 7(2): 172-190.

[87] Watts, Barry D. 1997. "Ignoring Reality: Problems of Theory and Evidence in Security Studies." Security Studies. 7(2): 115-171.

[88] Williams, George K. 1996. "The Shank of the Drill': Americans and Strategical Aviation in the Great War." Journal of Strategic Studies. 19(3): 381-431

[89] Zhuang, Jun, and Vicki M. Bier. 2007. "Balancing Terrorism and Natural Disasters-Defensive Strategy with Endogenous Attacker Effort." Operations Research. 55(5): 976-991.

[90] Zhuang, Jun, and Vicki M. Bier. 2011. "Secrecy and Deception at Equilibrium, with Applications to Anti-Terrorism Resource Allocation." Defence and Peace Economics. 22(1): 43-61. 